\title{
The coupled atmosphere-chemistry-ocean model SOCOL-MPIOM
}

\author{
S. Muthers ${ }^{1,2}$, J. G. Anet ${ }^{3, *}$, A. Stenke ${ }^{3}$, C. C. Raible ${ }^{1,2}$, E. Rozanov $^{3,4}$, S. Brönnimann ${ }^{2,5}$, T. Peter ${ }^{3}$, F. X. Arfeuille ${ }^{2,5,}$, \\ A. I. Shapiro ${ }^{4}$, J. Beer ${ }^{6}$, F. Steinhilber ${ }^{6}$, Y. Brugnara ${ }^{2,5}$, and W. Schmutz ${ }^{4}$ \\ ${ }^{1}$ Climate and Environmental Physics, University of Bern, Bern, Switzerland \\ ${ }^{2}$ Oeschger Centre for Climate Change Research, University of Bern, Bern, Switzerland \\ ${ }^{3}$ Institute for Atmospheric and Climate Science, ETH, Zurich, Switzerland \\ ${ }^{4}$ Physikalisch-Meteorologisches Observatorium Davos and World Radiation Center (PMOD/WRC), Davos, Switzerland \\ ${ }^{5}$ Institute of Geography, University of Bern, Bern, Switzerland \\ ${ }^{6}$ Swiss Federal Institute of Aquatic Science and Technology, Dübendorf, Switzerland \\ *now at: Swiss Federal Laboratories for Materials Science and Technology (Empa), Dübendorf, Switzerland
}

Correspondence to: S. Muthers (muthers@climate.unibe.ch)

Received: 19 March 2014 - Published in Geosci. Model Dev. Discuss.: 6 May 2014

Revised: 14 August 2014 - Accepted: 26 August 2014 - Published: 25 September 2014

\begin{abstract}
The newly developed atmosphere-oceanchemistry-climate model SOCOL-MPIOM is presented by demonstrating the influence of chemistry-climate interactions on the climate state and the variability. Therefore, we compare pre-industrial control simulations with (CHEM) and without (NOCHEM) interactive chemistry. In general, the influence of the chemistry on the mean state and the variability is small and mainly restricted to the stratosphere and mesosphere. The atmospheric dynamics mainly differ in polar regions, with slightly stronger polar vortices in the austral and boreal winter, respectively. The strengthening of the vortex is related to larger stratospheric temperature gradients, which are attributed to a parameterisation of the absorption of ozone and oxygen in different wavelength intervals, which is considered in the version with interactive chemistry only. A second reason for the temperature differences between CHEM and NOCHEM is related to diurnal variations in the ozone concentrations in the higher atmosphere, which are missing in NOCHEM. Furthermore, stratospheric water vapour concentrations substantially differ between the two experiments, but their effect on temperature is small. In both setups, the simulated intensity and variability of the northern polar vortex is inside the range of present-day observations.

Additionally, the performance of SOCOL-MPIOM under changing external forcings is assessed for the period 16002000 using an ensemble of simulations. In the industrial period from 1850 onward SOCOL-MPIOM overestimates the
\end{abstract}

global mean surface air temperature increase in comparison to observational data sets. Sensitivity simulations show that this overestimation can be attributed to a combination of factors: the solar forcing reconstruction, the simulated ozone changes, and incomplete aerosol effects and land use changes.

\section{Introduction}

In recent years, the stratosphere has received increasing attention due to its importance for our understanding and proper simulation of climate variability and climate change (Baldwin et al., 2007; Gerber et al., 2012). While most of the CMIP3 models include only a poorly resolved stratosphere (Cordero and Forster, 2006), 14 of 39 general circulation models (GCMs) participating in CMIP5 include a "high-top" atmosphere, with a fully resolved stratosphere (Flato et al., 2013). The importance of a well resolved stratosphere is highlighted in several studies (Gillett et al., 2002; Sigmond et al., 2004; Scaife et al., 2011; Hardiman et al., 2012). Moreover, some of the recent changes in the surface climate can only be reproduced when stratospheric chemistry and changes in the chemical composition of the stratosphere are considered in GCMs (Gillett and Thompson, 2003; Son et al., 2010; Thompson et al., 2011). 
Coupled climate models have been shown to be an important tool for understanding processes and feedbacks between the different components of the climate system, e.g. between the ocean and the atmosphere. To consider interactions between the atmospheric chemistry and the physical component of the atmosphere, atmospheric chemistry modules needs to be implemented in GCMs.

Most of the coupled chemistry-climate model (CCM) simulations so far were performed with prescribed sea surface temperatures (SSTs; e.g. Eyring et al., 2006) or simplified mixed-layer ocean models (e.g. Stenke et al., 2013a). However, in both approaches the climate system is not able to simulate the full response to, e.g. a strong external forcing like volcanic eruptions, since interactions between atmosphere and ocean are not considered (Kirchner et al., 1999). Moreover, global sea surface temperature (SST) data sets are only available back to the late 19th century.

The purpose of this study is to present the atmosphereocean-chemistry-climate model (AOCCM) SOCOLMPIOM. The atmospheric component of the model covers the atmosphere from the surface to the mesosphere and includes the interaction between the physical and the chemical components of the climate system. A particular focus of this study is on the influence of the stratosphere and the atmospheric chemistry on the tropospheric and surface climate.

The stratosphere interacts with the troposphere and plays an important role for the climate in the troposphere, at the surface, and for the oceanic circulation (e.g. Baldwin and Dunkerton, 1999; Graversen and Christiansen, 2003; Thompson et al., 2005; Reichler et al., 2012). The dynamics in the stratosphere furthermore, interacts with a large number of chemical processes - most importantly the ozone chemistry (Haigh, 1994; Shindell et al., 1999, 2001; Gillett and Thompson, 2003; Son et al., 2010; Thompson et al., 2011; Purich and Son, 2012; Varma et al., 2012). The interactions between the dynamics in the stratosphere and troposphere are most prominent in the northern and southern high latitudes during wintertime (Kodera, 1994). With the beginning of the polar night stratospheric temperatures start to decrease rapidly and the increasing equator-pole temperature gradient forces a strong and persistent zonal circulation. This polar vortex isolates the polar air masses and prevents the advection of warmer air towards the polar latitudes. Wind anomalies in the polar vortices influence the circulation in the troposphere (Baldwin et al., 1994; Baldwin and Dunkerton, 2001; Thompson et al., 2005), a phenomenon named stratosphere-troposphere coupling. Of particular relevance are unusually weak stratospheric zonal winds associated with a breakdown of the vortex (e.g. sudden stratospheric warmings). These disturbances are triggered by anomalously high wave activity propagating upward from the troposphere (Polvani and Waugh, 2004). Several processes were proposed to be involved in this wave propagation and to influence the stratosphere-troposphere coupling
(Song and Robinson, 2004; Gerber et al., 2012), but the underlying coupling mechanisms of stratosphere-troposphere interactions are still debated (Thompson et al., 2006; Gerber et al., 2012).

The winter climate at high latitudes is also closely related to modes of variability - the barotropic Northern Annual Mode (NAM) in the Northern Hemisphere (NH) and the barotropic Southern Annual Mode (SAM) in the Southern Hemisphere ( $\mathrm{SH})$. In the stratosphere, the NAM/SAM can be expressed by the variability of the polar vortices. The surface equivalent of the NAM is the Arctic Oscillation (AO). For the North Atlantic and European region the AO is closely related to the North Atlantic Oscillation (NAO) (Hurrell, 1995; Wanner et al., 2001; Pinto and Raible, 2012). The dynamical imprint of the tropospheric annular modes is a north-south shift in the position of the maximum winds or jets in the troposphere. Stratosphere-troposphere coupling events connect these stratospheric and tropospheric modes of variability, hence a stronger polar vortex co-varies with a positive phase of the $\mathrm{AO}$ and a weaker vortex with a negative phase of the AO (Baldwin and Dunkerton, 2001). Via the jet streams and their influence on tropospheric dynamics, the AO causally relates to, and thus is partially predictive of, weather patterns, with a negative $\mathrm{AO}$ index tending to be representative of high pressure in the polar region, weaker zonal winds, and greater movement of cold polar air into the mid-latitudes (Kolstad et al., 2010).

This paper is structured as follows. In Sect. 2 the model SOCOL-MPIOM is introduced and an overview of the experiments used in this study is given. In Sect. 3 the performance and characteristic of the AOCCM are described using results from a pre-industrial control simulation. The effect of atmospheric chemistry on the climate is assessed by comparing it to a simulation without interactive chemistry. Furthermore, we describe an ensemble of transient simulations for the period 1600-2000 to assess the behaviour of SOCOL-MPIOM under changing external forcings (Sect. 4). Finally, the results are discussed and summarised.

\section{Model and experimental design}

\subsection{Model}

The model consists of the chemistry-climate model SOCOL (SOlar Climate Ozone Links) coupled to the ocean-sea-ice model MPIOM by the OASIS3 coupler. The CCM SOCOL version 3 (Stenke et al., 2013b) is based on the middle atmosphere model MA-ECHAM5 version 5.4.01 (Roeckner et al., 2003) and a modified version of the chemistry model MEZON (Model for Evaluation of oZONe trends, Egorova et al., 2003).

MA-ECHAM5. The middle atmosphere version of ECHAM5 is a spectral GCM based on the primitive equations with temperature, vorticity, divergence, the surface 
pressure, humidity and cloud water as prognostic variables (Roeckner et al., 2003, 2006; Manzini et al., 2006). In the vertical dimension a hybrid sigma-pressure coordinate system is used.

The short-wave (SW) radiation code originates from the European Centre of Medium-Range Weather Forecasts (ECMWF) model IFS (Fouquart and Bonnel, 1980). The solar spectrum is split into six wavelength intervals, including three bands in the UV and visible ranges (185-250, 250$440,440-690 \mathrm{~nm})$ and three bands in the near-IR range (6901190, 1190-2380, 2380-4000 nm) (Cagnazzo et al., 2007). This SW scheme considers Rayleigh scattering, scattering and absorption by aerosols and clouds, and the absorption of solar irradiance by water vapour, ozone (both varying in space and time) as well as $\mathrm{CO}_{2}, \mathrm{~N}_{2} \mathrm{O}, \mathrm{CH}_{4}$ and $\mathrm{O}_{2}$. The latter are considered as uniformly mixed gases in MA-ECHAM5, but $\mathrm{CH}_{4}$ and $\mathrm{N}_{2} \mathrm{O}$ can optionally also vary in time and space (as is done in SOCOL).

The long-wave (LW) radiation scheme follows the rapid radiative transfer model (RRTM) (Mlawer et al., 1997), which calculates radiation fluxes and heating rates over 16 $\mathrm{LW}$ bands covering $10-3000 \mathrm{~cm}^{-1}$. In the computation absorption by water vapour, $\mathrm{CO}_{2}$, ozone, $\mathrm{N}_{2} \mathrm{O}, \mathrm{CH}_{4}, \mathrm{CFC}-11$, CFC-12, CFC-22, aerosols, as well as clouds are considered.

With the vertical resolution used in this study (39 levels up to $0.01 \mathrm{hPa}$ ), the model does not produce a Quasi-Biennial Oscillation (QBO) by itself. Therefore, a QBO nudging is applied by a linear relaxation of the zonal winds in the equatorial stratosphere (Giorgetta et al., 1999). The model assimilates the QBO input data between $20^{\circ} \mathrm{N}$ to $20^{\circ} \mathrm{S}$ in the horizontal and from $90 \mathrm{hPa}$ up to $3 \mathrm{hPa}$ in the vertical. ECHAM5 also includes a river run-off scheme (Hagemann and Duemenil, 1998; Hagemann and Duemenil-Gates, 2003) and simplified glacier calving, in the way that snow falling on ice sheets is instantaneously transferred to the next ocean grid cell.

SOCOL. An in-depth description of the model and the parameterisations used in the chemical module is given in Stenke et al. (2013b). In the following we only refer to the most important facts that are needed to understand the characteristic of the coupled model SOCOL-MPIOM. SOCOL consists of the MEZON and MA-ECHAM5 coupled by the 3-D temperature field and the radiative effect of the different greenhouse gases $\left(\mathrm{H}_{2} \mathrm{O}, \mathrm{O}_{3}, \mathrm{CH}_{4}, \mathrm{~N}_{2} \mathrm{O}\right.$ and $\left.\mathrm{CFCs}\right)$. In the chemical module, 41 chemical species can react together via 140 gas-phase reactions, 46 photolysis reactions, and 16 heterogeneous reactions. The latter appear either in or on aqueous sulfuric acid aerosols as well as on three types of polar stratospheric clouds, i.e. on supercooled ternary solution droplets, water ice, or nitric acid trihydrate. The transport of the chemical species is calculated by the advection scheme of MA-ECHAM5.

For SOCOL, the SW radiation code of MA-ECHAM5 has been modified in several aspects. In MA-ECHAM5 variations in the solar forcing are considered by variations in total solar irradiance (TSI). The ratio of the irradiance within the six SW bands to the TSI, however, is fixed. SOCOL directly uses spectral solar irradiance (SSI) as input, and, therefore, allows for a change in the spectral composition. As the absorption by oxygen and ozone in the Lyman-alpha, Schumann-Runge, Hartley and Higgins bands is only partially included in MA-ECHAM5, missing heating rates are parameterised using an approach similar to Egorova et al. (2004).

The time step for the dynamical processes and physical parameterisations in the model is $15 \mathrm{~min}$ with a spectral truncation of T31. However, to reduce the computational demand, full radiative transfer calculations are called - simultaneously with the chemistry routines - every 2 hours. Over the 2-hour interval the heating rates are estimated based on the 2-hourly radiative transfer calculations and the solar angle that is calculated at every time step.

SOCOL considers the climatic effects of stratospheric sulfate aerosols. For heterogeneous reactions on sulfate aerosols surface area densities (SAD) need to be prescribed. The aerosol optical properties include extinction coefficients, the asymmetry factor and single scattering albedo for each wavelength interval. Both, optical properties and SAD are prescribed, e.g. using the output of a microphysical model. In the troposphere, only the radiative aerosol effect is taken into account. Here, 10 different aerosol types are considered, including carbon aerosols, dust particles, sea salt and sulfate aerosols.

Precipitation of energetic particles into the atmosphere is simulated by different parameterisations for galactic cosmic rays (GCRs), low energetic electrons (LEE) and solar energetic proton (SEP) events (Calisto et al., 2011; Rozanov et al., 2012). The routines are designed in a way that from the known ionisation rate distributions, a certain amount of $\mathrm{N}$ (GCR, SPE, LEE), NO (GCR, SPE, LEE) and OH (GCR, SPE) is produced.

The interactive coupling between chemistry and dynamics can be deactivated, which disables chemistry-climate interactions in the model (SOCOL-MPIOM_nochem). In this case prescribed 3-D ozone concentrations are used for the radiative transfer calculations. The ozone fields can originate, e.g. from a model simulation with interactive chemistry. By forcing the model with an ozone field provided on the model grid, artefacts related to the vertical interpolation from pressure to model levels can be avoided. In contrast to many other models, SOCOL without interactive chemistry does not use zonally averaged ozone concentrations, as this has be shown to negatively bias simulated stratospheric climate, and also tropospheric dynamics (Waugh et al., 2009). Zonally averaged ozone concentrations also might influence the propagation of planetary waves (Gabriel et al., 2007). In the setup without interactive chemistry SOCOL is nearly identical to MA-ECHAM5, except for the consideration of spectral solar irradiance in the SW scheme mentioned above. The additional heating by absorption in the Lyman-alpha, SchumannRunge, Hartley and Higgins bands is by default deactivated. 
MPIOM. The oceanic component consists of the ocean model MPIOM (Marsland, 2003; Jungclaus et al., 2006), which includes a sea-ice component. It uses an Arakawa C grid with the North Pole shifted to Greenland and the South Pole centred over Antarctica. Shifting the poles towards land surfaces avoids numerical singularities at the North Pole and allows a higher resolution in the deep water formation regions in the North Atlantic. The grid has a nominal resolution of $3^{\circ}$, that varies between 22 and $350 \mathrm{~km}$. In the vertical the grid is divided into 40 levels with decreasing resolution from the surface to the bottom. The time step of the calculations in the ocean model is $144 \mathrm{~min}$ in this setup.

Atmosphere-ocean coupling. Both components, the atmosphere and the ocean, are coupled every $24 \mathrm{~h}$ using the OASIS3 coupler (Budich et al., 2010; Valcke, 2013). At the beginning of each model day the coupler exchanges momentum, heat, freshwater fluxes, as well as information on the SSTs, sea-ice extent, and snow cover on sea ice between the atmosphere and the ocean. No flux correction is needed in the coupling process.

\subsection{Experiments}

To assess the influence of the interactive chemistry on the climate state a 1400 year long pre-industrial (AD 1600) control simulation with interactive chemistry (CHEM) is compared to a simulation under the same set of boundary conditions, but without chemistry-climate interactions (NOCHEM). Furthermore, an ensemble of transient simulations, i.e. with varying boundary conditions, covering the period AD 1600-2000 is performed. An overview of the experiments is given in Table 1 .

\subsubsection{Control simulations}

For the control experiment, SOCOL is run in a horizontal resolution of T31 (approx. $\left.3.75^{\circ} \times 3.75^{\circ}\right)$ and with 39 vertical levels, resolving the atmosphere up to $0.01 \mathrm{hPa}$ (approx. $80 \mathrm{~km}$ ). The ocean component is branched from the year AD 1600 of a transient millennium simulation with the ECHAM5-MPIOM (Jungclaus et al., 2010). The atmospheric and chemistry components are initialised by presentday conditions, which adjust to the pre-industrial climate state within one to two decades.

In the control simulation all forcings are held constant at $\mathrm{AD} 1600$ conditions $\left(\mathrm{CO}_{2}: 276.4 \mathrm{ppm}, \mathrm{CH}_{4}: 692.7 \mathrm{ppb}\right.$, $\mathrm{N}_{2} \mathrm{O}: 269.0 \mathrm{ppb}$ ), except for volcanic aerosols, where the unperturbed year 1599 is chosen. For the land-surface boundary condition we use the forcing from the ECHAM5 package, representing present-day values (Hagemann, 2002). The QBO is nudged towards an idealised formulation based on Brönnimann et al. (2007) to avoid an unrealistic dominance of a westerly or easterly QBO phase.

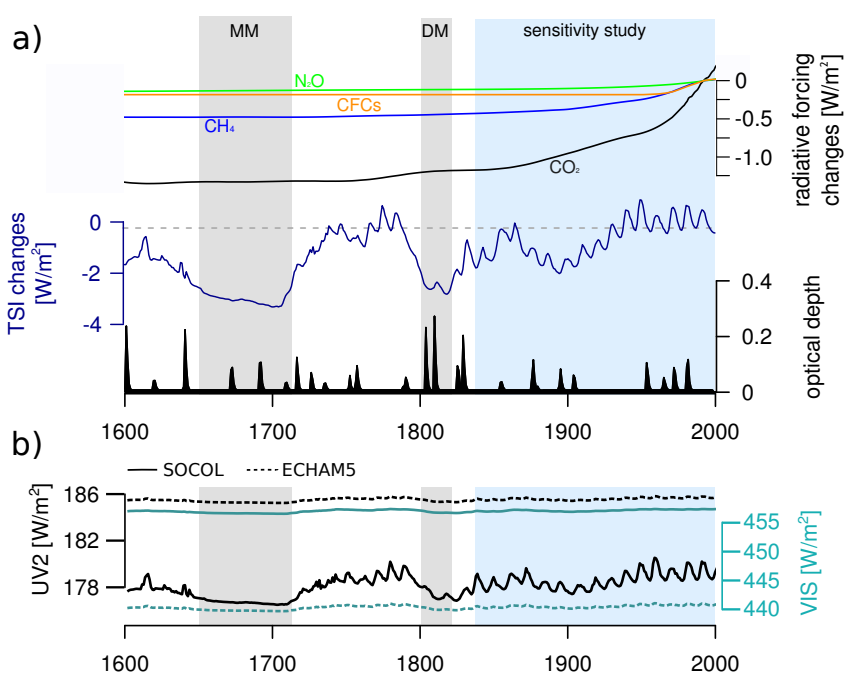

Figure 1. (a) Overview of the major external forcings applied in the transient simulations. Top: time series of the radiative forcing from major greenhouse gases $\mathrm{CO}_{2}, \mathrm{CH}_{4}, \mathrm{~N}_{2} \mathrm{O}$ and $\mathrm{CFCs}$ (calculated as in Ramaswamy et al., 2001); for CFCs the sum of CFC-11 and CFC22 is shown as representative forcing; values are expressed as deviations of the radiative forcing from the 1990 value. Middle: total solar irradiance calculated from the spectral solar irradiance reconstruction of Shapiro et al. (2011) (upper envelope of the uncertainty range). Bottom: volcanic forcing as global annual mean aerosol optical depth in the visible band (Arfeuille et al., 2014); three periods are highlighted - MM: late Maunder Minimum (1645-1715); DM: Dalton Minimum (1800-1820); and the period used in the sensitivity simulations (1840-2000, Sect. 4.2). (b) Time series of the SSI reconstruction (Shapiro et al., 2011) for the UV2 (250-400 nm) and visible (440-690 nm) spectral band (solid line) and in ECHAM5 when the same TSI is applied (dashed line).

SSI values for the year AD 1600 are based on the spectral solar reconstruction of Shapiro et al. (2011). The irradiance values for the six SW bands differ from the ratios used in ECHAM5 (Fig. 1b). In the UV region $(<440 \mathrm{~nm})$, considerably less energy is prescribed in SOCOL (differences $>$ $6 \mathrm{~W} \mathrm{~m}^{-2}$ in UV2). In the visible band (440-690 nm) the energy input is higher in SOCOL than in ECHAM5. Differences in this spectral interval are of the order of $16 \mathrm{~W} \mathrm{~m}^{-2}$. Between 690-1190 nm and 2380-4000 nm, the energy input is again larger in ECHAM5 $\left(+5.5 \mathrm{~W} \mathrm{~m}^{-2}\right.$ and $+4.5 \mathrm{~W} \mathrm{~m}^{-2}$, respectively), whereas for the interval $1190-2380 \mathrm{~nm}$ larger SSI values are prescribed in SOCOL $\left(+3.5 \mathrm{~W} \mathrm{~m}^{-2}\right)$.

With these differences in the spectral composition the new SOCOL-MPIOM experiences a positive surface air temperature (SAT) drift when a TSI of $1367 \mathrm{~W} \mathrm{~m}^{-2}$ (as in ECHAM5-MPIOM) is assumed. A tuning of the model is therefore required and the TSI as tuning parameter chosen. To estimate the optimal TSI value, a number of 200 year experiments with constant TSI reductions from 0 , $-2,-4, \ldots,-18 \mathrm{~W} \mathrm{~m}^{-2}$ relative to the reference value of $1367 \mathrm{~W} \mathrm{~m}^{-2}$ are performed. All experiment are forced by 
Table 1. Overview of the experiments used in this study. "Chemistry" indicates the usage of the interactive chemistry module. "Type" denotes whether the experiment is performed as an experiment with invariant boundary conditions (invar.) or as transient simulation with time-varying boundary conditions (trans).

\begin{tabular}{|c|c|c|c|c|c|}
\hline & Length/period & Chemistry & Solar amplitude & Type & Forcings \\
\hline CHEM & 1400 years & yes & const. & invar. & const. AD 1600 \\
\hline NOCHEM & 222 years & no & const. & invar. & const. AD 1600 \\
\hline $1 \% \mathrm{yrCO}_{2}$ & 80 years & yes & const. & invar. & const. $\mathrm{AD} 1600$, except for $\mathrm{CO}_{2}$ \\
\hline $1 \% \mathrm{yrCO}_{2 \_} \_\mathrm{nc}$ & 80 years & no & const. & invar. & const. AD 1600 , except for $\mathrm{CO}_{2}$ \\
\hline $4 \times \mathrm{CO}_{2}$ & 150 years & yes & const. & invar. & const. AD 1600 , except for $\mathrm{CO}_{2}$ \\
\hline $4 \times \mathrm{CO}_{2} \_\mathrm{nc}$ & 150 years & no & const. & invar. & const. $\mathrm{AD} 1600$, except for $\mathrm{CO}_{2}$ \\
\hline $\mathrm{EH} 5 \_1 \% \mathrm{yrCO}_{2}$ & 80 years & no & const. & invar. & const. $\mathrm{AD} 800$, except for $\mathrm{CO}_{2}$ \\
\hline EH5_4 $\times \mathrm{CO}_{2}$ & 150 years & no & const. & invar. & const. AD 800, except for $\mathrm{CO}_{2}$ \\
\hline TR1 & $1600-2000$ & yes & medium & trans. & all \\
\hline TR2 & $1600-2000$ & yes & medium & trans. & all \\
\hline SOLAR & $1840-2000$ & no & medium & trans. & const. AD 1840, except for solar \\
\hline GHG & $1840-2000$ & no & const. & trans. & const. AD 1840 , except for $\mathrm{GHG}$ \\
\hline AERO & $1840-2000$ & no & const. & trans. & const. AD 1840 , except for aerosols \\
\hline OZONE & $1840-2000$ & no & const. & trans. & const AD 1840, except for ozone \\
\hline FULL & $1840-2000$ & no & medium & trans. & all \\
\hline
\end{tabular}

constant AD 1600 boundary conditions and started from the same initial state. The simulations with the smallest global mean SAT drift is continued for another 1200 years and used as control simulation, with a solar constant of $1355 \mathrm{~W} \mathrm{~m}^{-2}$. This value is meant to represent 1600 conditions. With the solar reconstruction of Shapiro et al. (2011), which is used in the transient simulations (see below), this corresponds to a TSI of $1358.7 \mathrm{~W} \mathrm{~m}^{-2}$ for the year 1990. Therefore, the new TSI value for SOCOL-MPIOM agrees reasonably well with the most recent TSI estimate of $1360.8 \pm 0.5 \mathrm{~W} \mathrm{~m}^{-2}$ by Kopp and Lean (2011).

To assess the influence of chemistry-climate interactions on the climate state and its variability, a second control experiment with SOCOL-MPIOM_nochem is performed (NOCHEM). This simulation is branched off 1178 years after the start of the interactive simulation. The length of this experiment is 222 years. Both simulations are driven by the same external forcings and boundary conditions, except for the parameterisations, which are not considered in NOCHEM. $\mathrm{CH}_{4}$ and $\mathrm{N}_{2} \mathrm{O}$ are considered as uniformly mixed gases with the same global average concentrations as in CHEM. Furthermore, for the radiative calculations ozone values need to be prescribed in NOCHEM. Here, a 3-D daily mean ozone climatology calculated over the simulation years 1178 to 1399 (length 222 years) of CHEM is used.

The control simulations are needed to (a) assess a potential underlying temperature drift due to the coupling of the model components, (b) as initial conditions for the transient simulations, and (c) to characterise the climatic impact of the interactively coupled chemistry. Due to the high computational demand of the chemistry computations and the long adjustment time of the ocean it was not possible to perform a second control simulation for 1990 conditions, as it is usually recommended for model evaluation studies.

\subsubsection{Climate sensitivity experiments}

Two types of experiments are used to analyse the climate sensitivity of SOCOL-MPIOM to increasing $\mathrm{CO}_{2}$ concentrations (Table 1). The transient climate response (TCR) is estimated using an experiment with $1 \% \mathrm{yr}^{-1} \mathrm{CO}_{2}$ increase until a $\mathrm{CO}_{2}$ doubling is reached (Cubasch et al., 2001). The TCR is then defined by the global mean SAT change in the $20 \mathrm{yr}$ period around the year of the $\mathrm{CO}_{2}$ doubling in comparison to a control simulation. Furthermore, we estimate the equilibrium response of the model following the approach by Gregory et al. (2004). In this case, the coupled model is forced by an instantaneous quadrupling of the $\mathrm{CO}_{2}$ concentrations and the equilibrium climate sensitivity (ECS) is estimated based on a linear relationship between the top-ofthe-atmosphere radiative flux imbalance and the global mean SAT change after a simulation length of 150 years.

Both experiments are performed with and without interactive chemistry, with initial conditions from CHEM (model year 1178) and representing a pre-industrial climate state. The experiments without interactive chemistry use a ozone climatology from CHEM, similar to the NOCHEM simulation. For the abrupt quadrupling of $\mathrm{CO}_{2}$ a 30-year atmosphere-only simulation with climatological SSTs and sea-ice cover are used as independent estimate of the adjusted radiative forcing. This experiment is performed with interactive chemistry only.

Furthermore, we conduct both types of sensitivity experiments with ECHAM5.4/MPIOM at T31 with 19 vertical levels and a nominal $3^{\circ}$ resolution of the ocean. These experiments are initialised from a control run used to initialise 
the millennium simulations of Jungclaus et al. (2010). This simulation represents perpetual AD 800 conditions. Therefore, the $\mathrm{CO}_{2}$ concentration slightly differs, with $278 \mathrm{ppm}$ at the beginning of the ECHAM5-MPIOM experiments and $276.4 \mathrm{ppm}$ for the SOCOL-MPIOM runs.

\subsubsection{Transient simulations}

Two transient simulations with SOCOL-MPIOM for the period AD 1600-2000 are started from initial conditions of the CHEM control simulation. In the following we refer to the transient experiments as TR1 and TR2. The two experiments are initialised from the CHEM simulation (model year 450 and 500).

An overview of the external forcings is given in Fig. 1. Greenhouse gas (GHG) forcings $\left(\mathrm{CO}_{2}, \mathrm{CH}_{4}\right.$ and $\left.\mathrm{N}_{2} \mathrm{O}\right)$ are taken from the PMIP3 database (Etheridge et al., 1996, 1998; Ferretti et al., 2005; MacFarling-Meure et al., 2006). The concentration of the ozone-depleting substances (ODSs) are taken from the CMIP5 database and before 1850 only naturally produced ODSs are prescribed. The solar forcing follows the SSI reconstruction by Shapiro et al. (2011), which is shown as total solar irradiance (TSI) in Fig. 1. In comparison to many other state-of-the-art solar reconstructions, this reconstruction is characterised by a larger amplitude (compare Schmidt et al., 2012), with a TSI difference between Maunder Minimum (MM, 1645-1715) and present day of $6 \pm 3 \mathrm{~W} \mathrm{~m}^{-2}$. Since this large amplitude is currently controversially discussed, we selected a solar forcing that represents the upper boundary of the uncertainty of the SSI reconstruction. Note that compared to other recent estimates a TSI difference of $3 \mathrm{~W} \mathrm{~m}^{-2}$ between MM and present day is still larger than in all other recent reconstructions. For example, in Steinhilber et al. (2009) the TSI difference between MM and present day is only $0.9 \pm 0.4 \mathrm{~W} \mathrm{~m}^{-2}$. Other solar-related forcings, like photolysis rates or the input for the additional heating by oxygen or ozone absorption, are based on the SSI data set.

The applied stratospheric aerosol data set (Fig. 1) is described in Arfeuille et al. (2014). Tropospheric aerosols are based on CAM3.5 simulations with a bulk aerosol model driven by fixed SSTs and the 1850-2000 CMIP5 emissions (S. Bauer, personal communication, 2011). Before 1850, the aerosol concentrations are scaled by the world population except for $10 \%$ of the presumed 1990 biomass burning aerosols, which are considered natural.

The emissions of $\mathrm{CO}$ and $\mathrm{NO}_{\mathrm{x}}$ are based on the CMIP5 data sets, which are available from 1850 onward. Before 1850 the anthropogenic fraction is linearly scaled with the world population. Biomass burning emissions are assumed to be constant over time. Emissions from shipping are linearly projected back to 1800 ; before 1800 they are set to zero.

The land surface data are kept at present-day values as in the control simulation (Hagemann, 2002). For the QBO nudging, the reconstruction from Brönnimann et al. (2007) was extended back in time to cover the full period 16002000, assuming an idealised QBO cycle.

The cosmic ray intensity is reconstructed based on the solar modulation potential (Steinhilber et al., 2008). Available observations for solar proton events (SPEs) are used for the periods 1963-2008 (Jackman et al., 2009). Before 1963 SPEs are randomised using a return-period based analysis of the last 45 years, and weighted with the Ap index, an index of the geomagnetic activity. The $\mathrm{NO}_{\mathrm{x}}$ influx, finally, is reconstructed based on the Ap and the Aa indices, which are themselves reconstructed using sunspot numbers (Baumgaertner et al., 2009). Palaeo-magnetic data sets (C. Finlay, personal communication, 2010) are applied to the model to take into account the evolution of the geomagnetic field.

In the analysis all transient simulations are detrended by subtracting the underlying positive trend estimated from the control simulation.

\subsubsection{Sensitivity simulations}

The contributions from different external forcings to the SAT increase from 1850 to 2000 are assessed by a set of sensitivity experiments with SOCOL-MPIOM_nochem (Table 1). In these simulations specific forcings are either held constant at pre-industrial levels or prescribed in a transient way. All simulations are initialised from year 1840 of the transient simulation TR1.

Using SOCOL-MPIOM_nochem allows us to use fixed ozone concentrations at pre-industrial levels or to prescribe the ozone field from our transient simulations, such that the radiative effect of the simulated ozone changes can be assessed. The following sensitivity runs are performed:

- SOLAR: In this experiment only the solar-related forcing changes.

- GHG: For this experiment only the major GHGs $\left(\mathrm{CO}_{2}\right.$, $\mathrm{CH}_{4}$, and $\mathrm{N}_{2} \mathrm{O}$ ) are time varying (see Fig. 1a), except for CFCs.

- AERO: Only stratospheric and tropospheric aerosols change.

For those experiments ozone concentrations are held constant at pre-industrial levels. Additionally,

- OZONE: In this experiment ozone is used as the only time-varying forcing. The ozone concentrations are extracted from TR1, but the concentrations in the second transient experiment are similar.

- FULL: All major external forcings (solar, GHGs, aerosols, ozone) are included in this simulation.

For each forcing a single experiment is performed. The forcing from CFCs is not considered in the sensitivity experiments. 

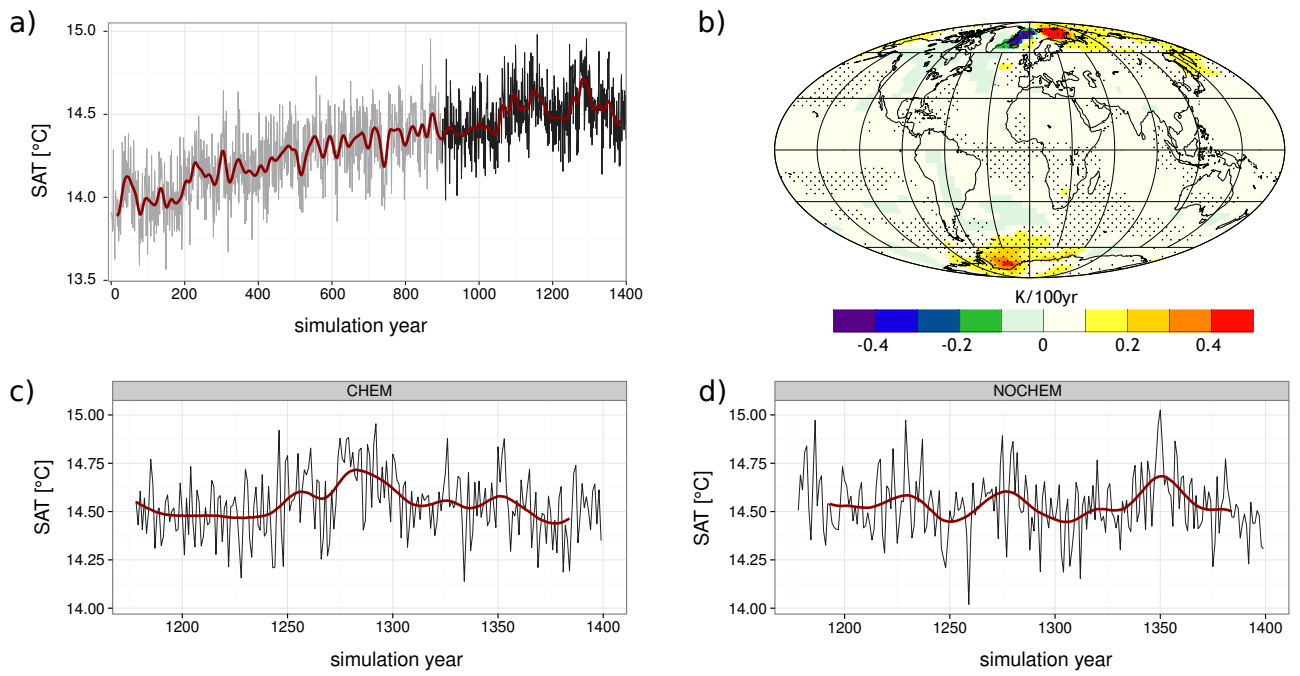

Figure 2. (a) Time series of the global mean surface air temperature (SAT) as annual mean values (black) and 31-year low-pass filtered values (red) for the simulation with interactive chemistry (CHEM). (b) Linear temperature trends in K/100 yr for the last 500 years in CHEM (indicated by black lines in (a)). Regions with significant trends are stippled. (c, d) Time series of the global mean $2 \mathrm{~m}$ air temperature as annual mean values (black) and 31-year low-pass filtered values (red) for the simulation with (CHEM) and without (NOCHEM) interactive chemistry over the common 222-year period.

\subsection{Observational data sets}

To evaluate the simulated climate different observational data sets are used throughout this study. Stratospheric temperatures and dynamics of the control simulation are compared to the two reanalysis products of the European Centre for Medium-Range Weather Forecasts (ECMWF), ERA40 (Uppala et al., 2005) and ERA Interim (Dee et al., 2011). ERA40 covers the period 1957-2002, while for ERA Interim the years 1979-2013 are considered.

The simulated SAT increase since the second half of the 19th century is compared to two global SAT data sets and a reanalysis product. The Goddard Institute for Space Studies Surface Temperature analysis (GISTEMP) contains a spatial land and ocean surface temperature analysis for the period 1880-2013 (Hansen et al., 2010). The data set is solely based on instrumental records from meteorological stations, ships, buoys, and other. The data from land stations are corrected for urban heat island effects using satellite observations. SSTs are based on the NOAA data set ERSST (Smith et al., 2008). The second data set is from the Climatic Research Unit at the Hadley Centre of the UK Met Office (HadCRUT4). It is also based on instrumental temperature records and covers the period 1850-2013 (Brohan et al., 2006). HadCRUT4 makes use of the SST data set HadSST3 for the conditions over oceans (Kennedy et al., 2011). Additionally, we use the 20th century reanalysis (20CR; Compo et al., 2011). By assimilating only sea level pressure, SST and seaice information (HadISST; Rayner et al., 2003) as boundary conditions, 20CR generates a physically consistent, 3-D picture of the atmosphere with high temporal resolution. 20CR contains 56 ensemble members, to consider uncertainties in the boundary conditions. The reanalysis covers the period 1871-2010.

\section{Pre-industrial model climatology and imprint of atmospheric chemistry}

In this section, the mean climate state and the most important variability patterns in the pre-industrial (AD 1600) control simulation of SOCOL-MPIOM as well as the impact of chemistry-climate interactions are analysed.

The evolution of the global mean SAT in CHEM is shown in Fig. 2. With $14.45^{\circ} \mathrm{C}$ the simulated global mean SAT for CHEM is higher than the observed pre-industrial mean (1850-1890) of $13.7 \pm 0.2{ }^{\circ} \mathrm{C}$ (Brohan et al., 2006). However, the value is similar to a comparable model run with ECHAM5-MPIOM (Fig. 4 in Mauritsen et al., 2012). Despite the tuning approach described above, there is still a continuous positive drift of $0.037 \mathrm{~K} / 100 \mathrm{yr}$, averaged over the last 500 model years. The temperature trend in the SH $(0.038 \mathrm{~K} / 100$ years $)$ is slightly larger than in the $\mathrm{NH}$ $(0.036 \mathrm{~K} / 100$ years $)$, and more pronounced over land than over the ocean. The largest SAT increase is found in polar regions, especially in the Barents and Weddell seas, caused by an amplifying sea-ice feedback. The surface warming also influences the ocean. A positive temperature trend is present at all levels down to the deep ocean, reaching, e.g. $0.05 \mathrm{~K} / 100$ years at a depth of $3500 \mathrm{~m}$.

The global mean SAT in CHEM and NOCHEM is very similar, besides some variations related to the model's internal variability (Fig. $2 \mathrm{c}$ and d), indicating that the interactive 

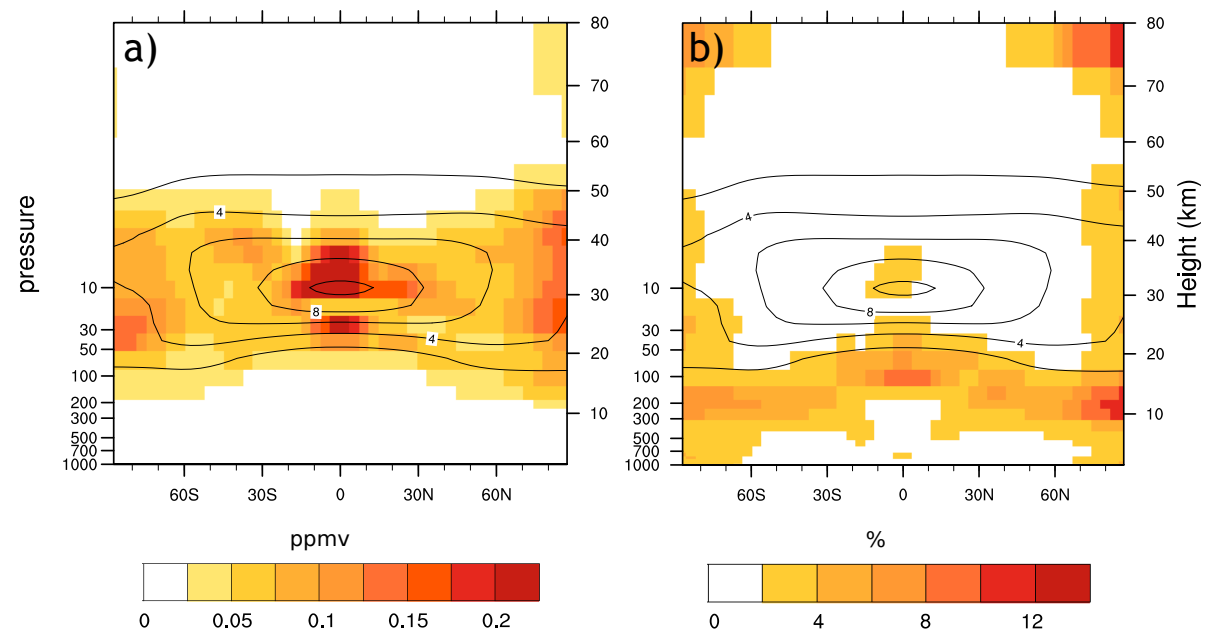

Figure 3. Variability in the annual mean zonally averaged ozone mixing ratios in CHEM. (a) Standard deviation (in ppmv). (b) Variability expressed as standard deviation normalised by the long-term mean (given as percentages). Contours show the long term-mean ozone concentrations.

chemistry does not significantly affect the mean climate. Furthermore, the SAT drift over the common 222-year period is no longer significant. However, the oceanic temperatures are still not in equilibrium.

The ongoing temperature drift indicates that the model has not yet reached equilibrium. The top-of-the-atmosphere (TOA) radiation balance is still characterised by a positive imbalance of $1.6 \mathrm{~W} \mathrm{~m}^{-2}$, averaged over the last 100 years of the simulations. However, most climate models do not exactly conserve energy (Mauritsen et al., 2012). Tests with SOCOL coupled to a mixed layer ocean model reveal a TOA imbalance of $1.45 \mathrm{~W} \mathrm{~m}^{-2}$ - a further slight adjustment of the temperatures is therefore likely.

In the following the differences in the mean climate and its variability between CHEM and NOCHEM for different variables and components of the climate system are presented.

\subsection{Stratospheric changes with interactive chemistry}

\subsubsection{Ozone variability}

A detailed evaluation of the chemistry in SOCOL3 is given by Stenke et al. (2013b). Here, we focus only on the simulated variability in stratospheric ozone concentrations and their possible influence on climate. While CHEM considers ozone fluctuations on all timescales, the climatological mean ozone field applied in NOCHEM does not account for any variability on timescales shorter than 1 day and longer than 1 year.

The time series of global mean ozone mixing ratios at different pressure levels reveal that variability takes place on many time-scales, from day-to-day up to the decadal scale. A pronounced and significant 2.3-year periodicity is found, related to the QBO. Note that the applied QBO nudging in
SOCOL may weaken feedbacks between ozone and circulation changes.

In the zonal mean perspective the largest variability is found in the tropics at the altitude of the ozone maximum (Fig. 3a). Secondary maxima occur in the lower stratosphere in both polar regions. The normalised variability (Fig. 3b) is more pronounced in the polar stratosphere of both hemispheres compared to the tropics. The variability in the troposphere and mesosphere is in general very small and only reflected in the normalised anomalies. These variability maxima are found in the lower stratosphere, in particular in the tropics and polar latitudes, as well as in the polar mesosphere. Overall the interannual variability for particular seasons is larger than for the annual mean. In the NH polar stratosphere, the year-to-year variability during the winter season (DJF) exceeds $10 \%$. The variability of total column ozone reflects the pattern found for the zonal averages (not shown). The northern and southern polar regions are characterised by the highest interannual variability, with the north being more variable than the south. In the Arctic, variability is particularly pronounced during boreal winter and spring. Over Antarctica, largest variances are found mainly during the break-up of the polar vortex in spring.

\subsubsection{Temperatures}

The seasonal zonal mean differences in the temperature between CHEM and NOCHEM are presented in Fig. 4a. The largest temperature differences are found in the mesosphere, where CHEM is more than $3 \mathrm{~K}$ warmer. These differences are most pronounced in the summer season of the corresponding hemisphere. In the upper and middle stratosphere the temperatures are significantly higher in the mid-latitudes (30 to $50^{\circ}$ ) in both hemispheres, and significantly lower in polar regions (Student's $t$ test, $p \leq 0.05$ ). The positive differences 
a) temperature differences
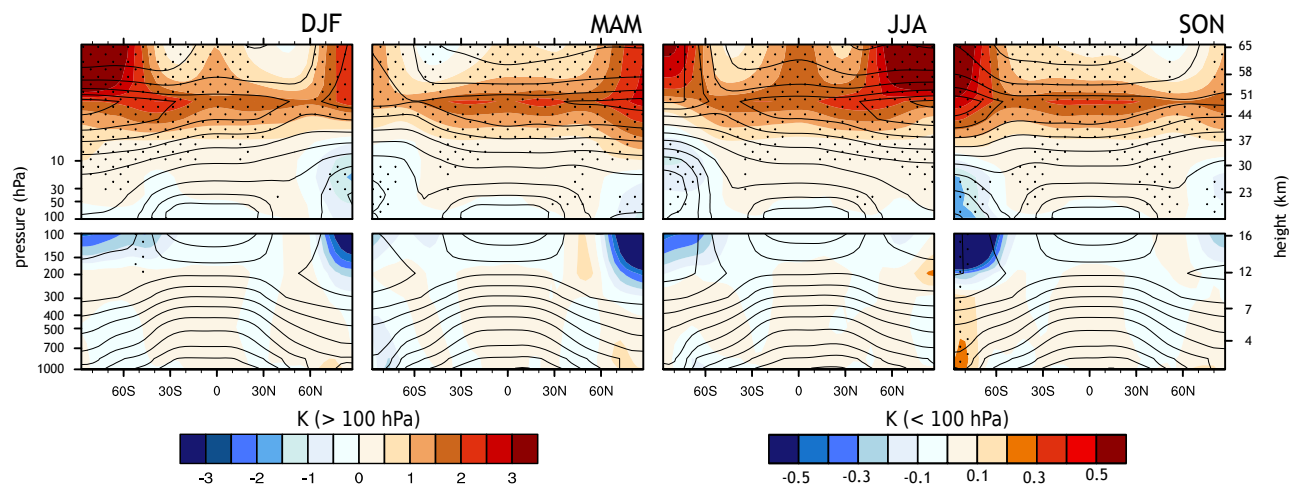

b) zonal wind differences
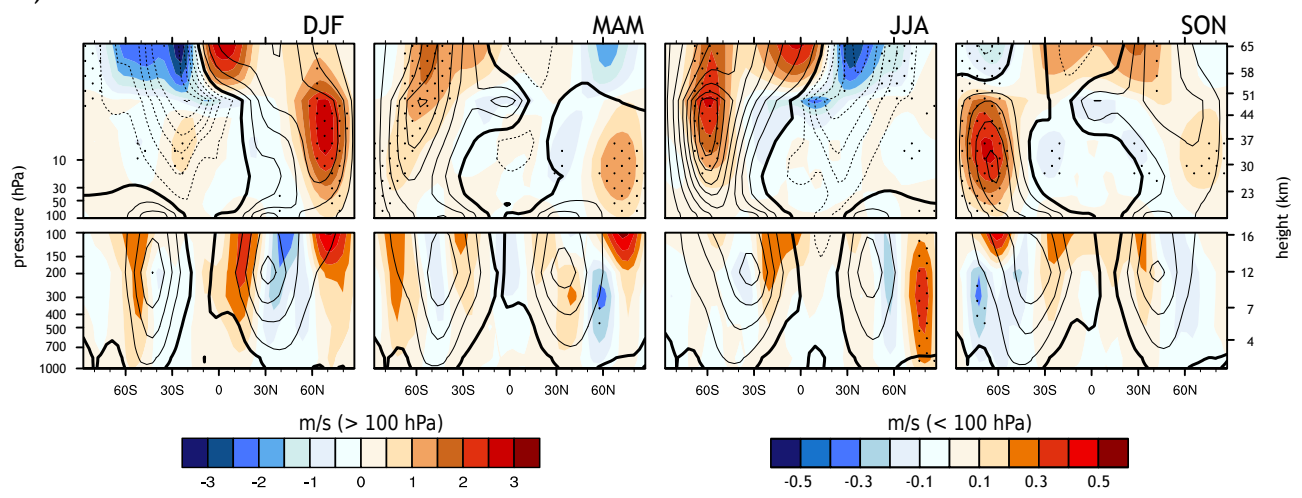

c) variance ratios
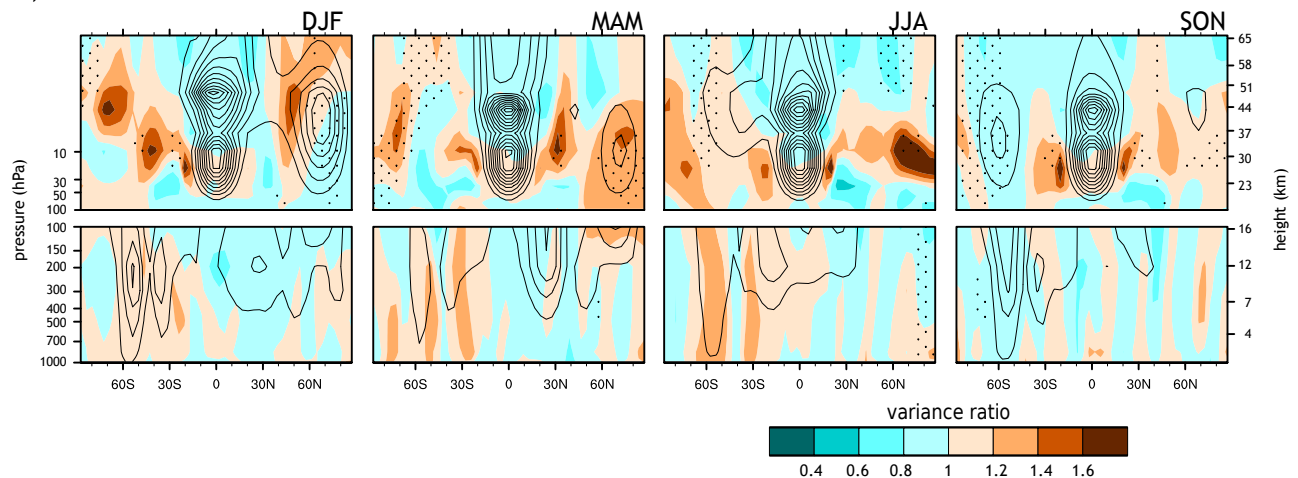

Figure 4. Zonal and seasonal mean anomalies between CHEM and NOCHEM, i.e. CHEM minus NOCHEM for (a) temperatures, (b) the zonal wind component and (c) the variance ratio of the zonal mean wind component between CHEM and NOCHEM, i.e. variance $(C H E M) /$ variance(NOCHEM). Atmospheric levels above (top) and below (bottom) $100 \mathrm{hPa}$ are displayed separately to improve readability in the lower atmosphere. Contours: seasonal means in CHEM with contours (a) from $230 \mathrm{~K}$ to $300 \mathrm{~K}^{\text {by }} 10 \mathrm{~K}$ and (b) $-50 \mathrm{~m} \mathrm{~s}^{-1}$ to $50 \mathrm{~m} \mathrm{~s}^{-1}$ by $10 \mathrm{~m} \mathrm{~s}^{-1}$. In (c) the seasonal variance in CHEM is shown, in contours from $0 \mathrm{~m}^{2} \mathrm{~s}^{-2}$ to $140 \mathrm{~m}^{2} \mathrm{~s}^{-2}$ by $25 \mathrm{~m}^{2} \mathrm{~s}^{-2}$ for levels above $100 \mathrm{hPa}$ and $0 \mathrm{~m}^{2} \mathrm{~s}^{-2}$ to $15 \mathrm{~m}^{2} \mathrm{~s}^{-2}$ by $3 \mathrm{~m}^{2} \mathrm{~s}^{-2}$ for levels below $100 \mathrm{hPa}$. Stippling: significant differences between the ensembles. In the case of the seasonal mean comparison (a, b) a Student's $t$ test is used. The variance comparison is based on an $F$ test. Test results with $p \leq 0.05$ are stippled. Differences are calculated over the common 222-year period.

are below $0.6 \mathrm{~K}$ and do not show a clear seasonal variation. The negative differences in the lower stratosphere are most pronounced and significant during winter and spring and reach up to $-1.5 \mathrm{~K}$.
The warmer upper stratosphere/mesosphere in CHEM results from a combination of different processes. The additional heating due to absorption in the Lyman-alpha, Schumann-Runge, Hartley and Higgins bands, which is not included in NOCHEM, is responsible for a pronounced heating of the higher atmosphere, especially during summer (not 
shown). Annual average temperatures in CHEM are up to $7 \mathrm{~K}$ higher, and the effect is visible at all latitudes in the mesosphere and upper stratosphere. Therefore, an additional cooling effect in the mesosphere is needed to create the pattern shown in Fig. 4.

This cooling effect is caused by interactions between the ozone chemistry and the SW radiation scheme. In the mesosphere ozone exhibits a pronounced diurnal cycle (Brasseur and Solomon, 2005), which is not considered in the daily mean ozone climatology prescribed in NOCHEM. During daytime ozone is destroyed by UV radiation. In the night the photolytic ozone destruction is missing and ozone concentrations increase. Differences between night and day can reach up to $15 \%$ in SOCOL. Consequently, the highest model levels in CHEM are colder during daytime, but this cooling cannot be compensated at night. The diurnal cycle of the ozone concentrations in the mesosphere has a cooling effect of around $5 \mathrm{~K}$, which is largest at $30^{\circ} \mathrm{N}$ and $30^{\circ} \mathrm{S}$.

An additional difference between CHEM and NOCHEM affects water vapour concentrations in the upper atmosphere (not shown). In the NOCHEM configuration transport from the troposphere is the only source of water vapour in the strato- and mesosphere, while CHEM additionally considers chemical water vapour production by the oxidation of $\mathrm{CH}_{4}$. In CHEM the summer hemisphere at altitudes above $40 \mathrm{~km}$ is up to $37 \%$ moister than in NOCHEM. The higher water vapour mixing ratios lead to a cooling of the higher atmosphere between $60^{\circ} \mathrm{S}$ and $60^{\circ} \mathrm{N}$. In the annual mean the maximum anomalies are around $1 \mathrm{~K}$. Maycock et al. (2011) reported a maximum cooling in the lower stratosphere after a uniform increase of stratospheric water vapour; however, the cooling effect in SOCOL-MPIOM is strongest in the upper stratosphere and mesosphere. This is probably because the water vapour difference between CHEM and NOCHEM is not uniform and the largest differences are found in the higher stratosphere. Further tests related to the impact of GCR, LEE and SEP events show that these parameterisations do not substantially affect atmospheric temperatures.

The lower and middle polar stratospheres are characterised by negative temperature differences during winter and spring. This cooling is accompanied by enhanced water vapour mixing ratios in the lower polar stratosphere in CHEM, which could explain the regional cold anomalies. However, with the current experimental setup, we cannot rule out the possibility of a dynamical origin of the cold anomalies, related to the changes in the polar vortex intensities explained below.

\subsubsection{Dynamics}

The differences in the zonal mean zonal wind reflect the changes in the meridional temperature gradients (Fig. 4b). Both polar vortices are significantly strengthened during winter and spring in the case of the simulation with chemistry-climate feedbacks. This vortex intensification
Table 2. Climatological indices for the winter (DJF) zonal mean zonal wind at $50 \mathrm{hPa}$ in different latitudes, similar to Driscoll et al. (2012). Climatological indices for CHEM and NOCHEM are calculated over the common 222-year period. Reanalysis values are based on ERA Interim for the period 1979-2013 (Dee et al., 2011) and ERA 40 for the years 1957-2002 (Uppala et al., 2005). Values given denote the average zonal wind speed in the given latitude range at $50 \mathrm{hPa}$ in $\mathrm{m} \mathrm{s}^{-1}$; the standard deviation is given in parentheses.

\begin{tabular}{lll}
\hline & $30^{\circ} \mathrm{S}-30^{\circ} \mathrm{N}$ & $55-65^{\circ} \mathrm{N}$ \\
\hline CHEM & $-2.4(3.6)$ & $23.1(7.7)$ \\
NOCHEM & $-2.4(3.5)$ & $22.5(7.8)$ \\
ERA Interim & $-3.7(5.1)$ & $19.0(8.6)$ \\
ERA 40 & $-3.8(5.1)$ & $19.1(8.1)$ \\
\hline
\end{tabular}

could also explain the colder conditions in CHEM in the SH and $\mathrm{NH}$ polar stratosphere, preventing meridional transport of warmer air into the vortex centre. Temperature and zonal wind changes are more pronounced in the SH. In the summer hemisphere, the changed temperature gradient forces a strengthening of the easterly circulation at mesospheric levels.

A comparison between model results and observations for the zonal wind component at $50 \mathrm{hPa}$ in the boreal winter season is given in Table 2. Similar to Driscoll et al. (2012), we average over the tropical latitudes $\left(30^{\circ} \mathrm{S}-30^{\circ} \mathrm{N}\right)$ and the northern mid-latitudes $\left(55-65^{\circ} \mathrm{N}\right)$. The reanalysis products ERA40 and ERA Interim, covering the period 1957-2002 and 1979-2013, respectively, are used for the comparison.

In tropical latitudes the modelled average wind conditions and the standard deviation are lower compared to ERA Interim. However, SOCOL-MPIOM agrees much better with ERA Interim than the CMIP5 models evaluated by Driscoll et al. (2012), which can be attributed to the QBO nudging implemented in the model. No significant difference is found between CHEM and NOCHEM for the tropics. The northern polar night jet is slightly, but significantly stronger $\left(0.6 \mathrm{~m} \mathrm{~s}^{-1}\right)$ in CHEM than in NOCHEM. The variability of the daily mean zonal wind component does not differ significantly between CHEM and NOCHEM. Compared to ERA Interim, SOCOL-MPIOM simulates stronger zonal winds with a slightly lower standard deviation. Still, the agreement is better than for most CMIP5 models evaluated by Driscoll et al. (2012). This agreement is particularly notable, since earlier studies suggested that the underestimation of stratosphere-troposphere coupling events after tropical volcanic eruptions may be related to a too strong and too stable northern polar vortex in many GCMs (Stenchikov et al., 2006; Driscoll et al., 2012). Although the different climate states, pre-industrial control vs. late 20th century, might bias the comparison there is confidence that SOCOL-MPIOM simulates wind conditions in the tropical and northern high latitudes reasonably well. Furthermore, the 
Table 3. Average number of SSWs per winter (NDJFM) following the definition of Charlton and Polvani (2007). SSWs for CHEM and NOCHEM are calculated over the common 222-year period. For comparison the reanalysis products ERA 40 (1957-2002) and ERA Interim (1979-2013) are used.

\begin{tabular}{lllllll}
\hline & Nov & Dec & Jan & Feb & Mar & $\sum$ \\
\hline CHEM & 0.12 & 0.07 & 0.07 & 0.14 & 0.23 & 0.59 \\
NOCHEM & 0.10 & 0.07 & 0.10 & 0.19 & 0.21 & 0.67 \\
ERA40 & 0.02 & 0.09 & 0.24 & 0.16 & 0.13 & 0.64 \\
ERA Interim & 0.00 & 0.12 & 0.18 & 0.26 & 0.21 & 0.76 \\
\hline
\end{tabular}

comparison between CHEM and NOCHEM reveals an influence of interactive ozone chemistry on the mean intensity of the northern winter polar vortex.

The stability of the northern polar vortex is closely related to sudden stratospheric warming events (SSWs). The total number of SSWs per winter in CHEM and NOCHEM is similar to ERA 40 and ERA Interim with the SSW definition of Charlton and Polvani (2007) (Table 3). The difference between ERA 40 and ERA Interim is due to the different periods; in the common period 1979-2002 the difference is negligible. With interactive chemistry fewer SSWs are simulated, which might be related to the stronger polar vortex in CHEM. However, the differences between the data sets are in no case statistically significant (statistical test following Charlton et al., 2007). Note that the more realistic simulation of SSWs is a major improvement to earlier versions of SOCOL (Fischer et al., 2008) and is attributed to a better representation of the stratospheric temperatures in the polar regions in winter and spring (Stenke et al., 2013b). The SSW frequency is also very similar to MAECHAM5 (Charlton et al., 2007). A caveat, however, is associated with the different reference periods used in the comparison.

Neglecting any interannual ozone variations in the simulation NOCHEM might affect different atmospheric quantities and reduce their variability on interannual timescales. Changes in the interannual variability of the zonal mean temperatures and zonal winds are described in the following. Therefore, the ratio of the two variances, i.e. $\frac{\operatorname{var}(\text { CHEM) }}{\operatorname{var}(\text { NOCHEM) }}$ is calculated. A ratio of 1 corresponds to no change, and values $<1$ ( $>1$ ) to a reduction (increase) of the variance due to interactive chemistry. The highest variability in the zonal wind is found in the tropical stratosphere for all seasons (contours in Fig. 4c), due to the QBO. Secondary maxima of the variability are found in the NH during DJF and MAM, related to the winter polar vortex. In the SH the variability of the polar vortex is lower, i.e. the vortex is more stable in the winter months. Still, a second maximum is found for austral spring in the vortex region. In the $\mathrm{NH}$, the variability in the winter vortex is enhanced around the vortex edge and reduced in the centre of the vortex in SOCOL with interactive chemistry. The slightly lower variability in the centre may be related to the overall stronger vortex. A significant increase in the variability in the northern polar vortex is found for the boreal spring season. In the $\mathrm{SH}$, the variability in the winter polar vortex is slightly (albeit significantly) higher in winter, but reduced in the following spring season.

In summary, the largest differences between the simulation with and without interactive chemistry are only indirectly related to the chemistry. With interactive chemistry the absorption of oxygen and ozone in different wavelength bands leads to enhanced heating rates in the upper atmosphere. This warming is compensated by interactions between the diurnal cycle of mesospheric ozone and the SW radiation scheme. Furthermore, stratospheric water vapour concentrations are considerably lower, since an important source of water vapour $\left(\mathrm{CH}_{4}\right.$ oxidation) is not considered in the NOCHEM model version. These differences affect the temperature distribution, the wind field and the polar vortices. However, the overall differences in the stratospheric climate are small.

\subsection{Tropospheric and surface changes}

In the troposphere, the only significant temperature difference is found during the austral spring season in southern high latitudes below $250 \mathrm{hPa}$ (Fig. 4a). This warming is related to differences in the cloud cover between CHEM and NOCHEM. During austral winter and spring significantly more clouds are formed polewards of $60^{\circ} \mathrm{S}$ and between 250 and $100 \mathrm{hPa}$ in CHEM, with differences up to $20 \%$ in the vertically integrated total cloud cover. These clouds are a consequence of the higher stratospheric water vapour concentrations due to the oxidation of $\mathrm{CH}_{4}$, and lead to a trapping of outgoing long-wave radiation and a warming of the air column below. The enhanced cloud occurrence and the related temperature anomalies peak in August. The tropospheric temperature anomaly is therefore still weak and not significant during austral winter, but has a clear and significant impact on the temperatures in austral spring.

Similar differences are found in the NH during boreal winter. However, here the effect is weaker than in the $\mathrm{SH}$, since the cooling of the polar stratosphere is smaller and fewer clouds are formed.

Differences in the tropospheric zonal mean wind reveal a more heterogeneous pattern. In the SH, the reduced meridional temperature gradient in spring causes a shift of the westerlies to the equator, with a significant reduction in the south and (insignificant) increases in the north. However, during austral summer and autumn the westerly circulation is stronger in the south (sign. in MAM). In the NH, a significant weakening of the westerlies at high latitudes is also found for MAM together with a strengthening in summer.

At the surface the differences between CHEM and NOCHEM are smaller and only a few significant changes are found (Fig. 5). In the Barents Sea, higher temperatures in CHEM are present during the entire year and related to less 

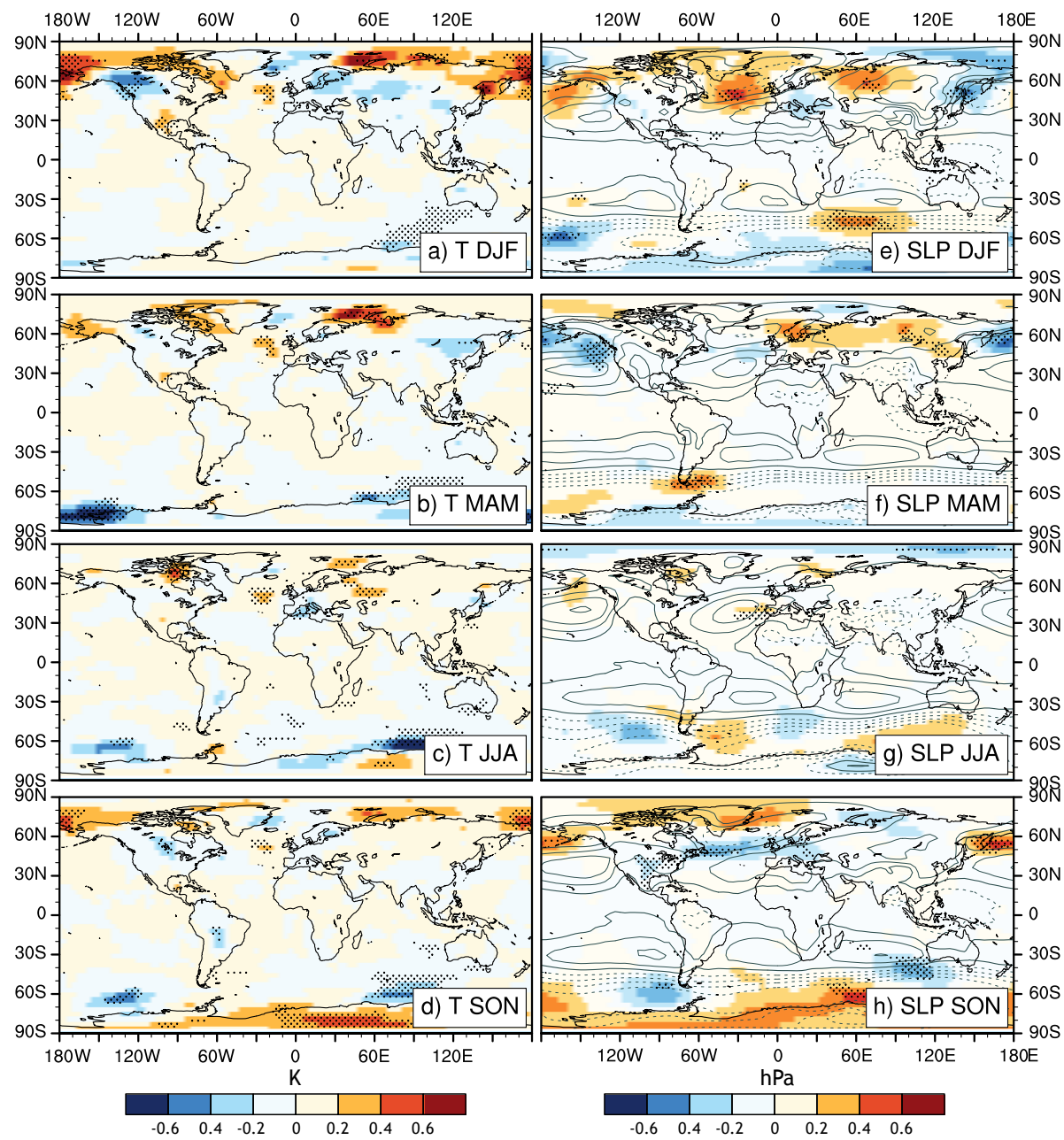

Figure 5. Differences in the seasonal mean SAT (left) and sea level pressure (right) between CHEM and NOCHEM. Seasons are displayed from top to bottom (DJF: a, e; MAM: b, f; JJA: c, $\mathbf{g}$; SON: d, h). Grey contours in the sea level pressure panels display the seasonal average field in CHEM. The significance of the anomalies is indicated by stipplings for $p \leq 0.05$ (Student's $t$ test).

sea ice (Fig. 5). The variability in the sea-ice cover in the Barents Sea is in general very large. The sea level pressure or wind patterns reveal no consistent changes that may help to explain the sea-ice differences. Temperature differences between CHEM and NOCHEM in this region are therefore probably related to internal processes in the ocean that modulate the inflow of warm Atlantic water into the Barents Sea basin and, consequently, the sea-ice cover and the surface temperatures.

In the SH high latitudes, the higher temperatures in CHEM during austral spring are related to the cloud cover differences as explained above. In the Southern Ocean, between Australia and Antarctica a cooling is present during the entire year.

In the North Atlantic sea level pressure (SLP) significantly increases in CHEM compared to NOCHEM (Fig. 5). In the North Pacific a significant reduction of the SLP is found for MAM and a significant increase for the SON season. No significant changes are found for the SLP field in the SH, except for austral spring, which is related to the temperature differences between CHEM and NOCHEM.

Besides changes in the mean climate, the missing interannual variability in the ozone concentration may also influence the variability at the surface. However, the surface temperatures do not show a systematic and significant change in the variability for any season (not shown). The variance ratio between CHEM and NOCHEM of the SLP field is shown in Fig. 6 and reveals some significant differences in regions with overall low variability and no differences in the regions of the classical centres of actions. For the ocean no significant differences between CHEM and NOCHEM are found, besides the above-mentioned sea-ice cover differences in the Barents Sea (not shown).

In summary, the influence of the interactive chemistry in the troposphere is regionally and seasonally limited. The largest difference between CHEM and NOCHEM, the 


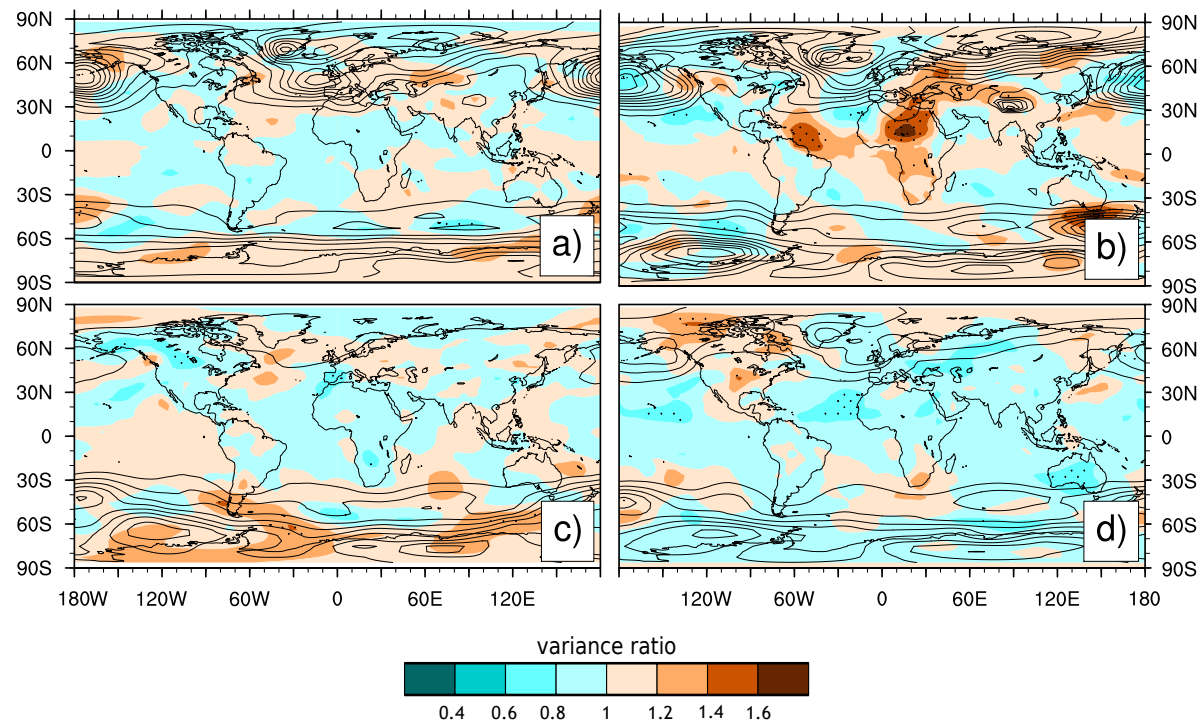

Figure 6. Variance ratio (i.e. variance $(C H E M) /$ variance $(N O C H E M)$ ) for the seasonal mean sea level pressure with (a) DJF, (b) MAM, (c) JJA, and (d) SON. Stippling: significant differences between the ensembles based on an $F$ test. Test results with $p \leq 0.05$ are stippled. Contours: seasonal variance in CHEM. Differences are calculated over the common 222-year period.

change in winter and spring climate over Antarctica, is related to the differences in stratospheric water vapour concentrations between the two experiments. Significant and consistent influences of the chemistry on the variability are rare.

\subsection{Climate sensitivity of SOCOL-MPIOM}

The transient climate response (TCR), which is estimated in experiments with continuous $1 \%$ per year $\mathrm{CO}_{2}$ increase until a doubling is reached after 70 years, is very similar in all models. SOCOL-MPIOM, SOCOL-MPIOM_nochem and ECHAM5-MPIOM have a TCR of $1.8 \mathrm{~K}$ (Table 4). These estimates show good agreement with the TCR values of the CMIP5 models (Fig. 7).

Larger differences are found for the equilibrium climate sensitivity (ECS). In the abrupt $4 \times \mathrm{CO}_{2}$ experiments the regression approach by Gregory et al. (2004) reveals an equilibrium global mean SAT response $(\Delta T)$ of $7.5 \mathrm{~K}, 8.0 \mathrm{~K}$ and $10.8 \mathrm{~K}$ for SOCOL-MPIOM, SOCOLMPIOM_nochem and ECHAM5-MPIOM, respectively. By $\Delta T / 2$ the corresponding ECS is $3.8,4.0$ and $5.4 \mathrm{~K}$. The ECS of SOCOL-MPIOM is considerably lower than the estimate for ECHAM5-MPIOM. A similar ECS estimate (10.8 K SAT increase in $4 \times \mathrm{CO}_{2}$ experiment, which was continued until equilibrium) was reported by $\mathrm{Li}$ et al. (2012).

A feedback analysis (Andrews et al., 2012) reveals larger contribution of the SW component to the overall feedback in ECHAM5-MPIOM (Table 4), which is related to a stronger reduction of sea ice, in particular in the $\mathrm{NH}$, and a stronger cloud cover reduction. The differences in the amount of sea-ice loss may partially be related to differences in the initial state of the experiments, with more $\mathrm{NH}$ sea ice in

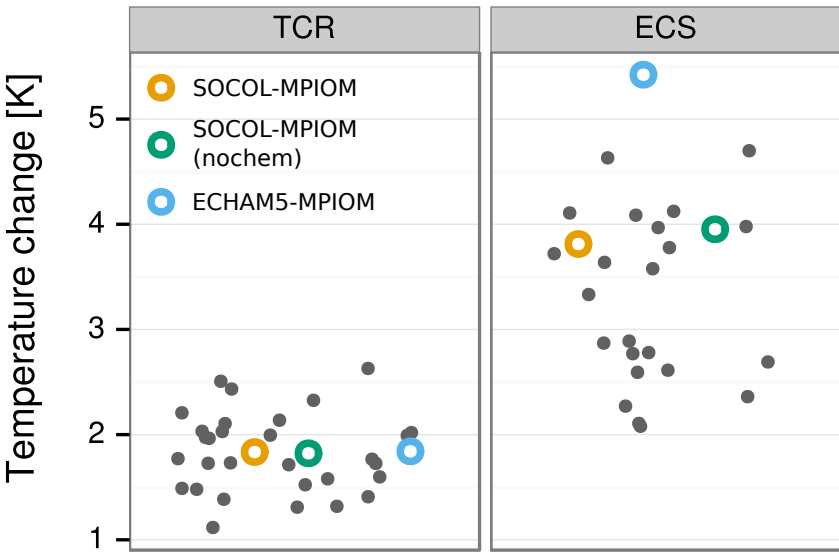

Figure 7. Comparison of the transient climate response (TCR, left) and the equilibrium climate sensitivity (ECS, right) for a doubling of $\mathrm{CO}_{2}$ for the CMIP5 (grey dots, Flato et al., 2013) to SOCOLMPIOM, SOCOL-MPIOM_nochem and ECHAM5-MPIOM (circles).

ECHAM5-MPIOM. The stabilising LW feedback is also smaller in ECHAM5-MPIOM. The comparison of SOCOLMPIOM and ECHAM5-MPIOM may also be biased by the differences in the vertical resolution of the atmosphere. The ECHAM5-MPIOM simulations were performed with 19 vertical levels (up to $10 \mathrm{hPa}$ ), while SOCOL-MPIOM was run with 39 levels (up to $0.01 \mathrm{hPa}$ ).

Moreover, the ECS is significantly lower $(\sim-7 \%)$ with interactive chemistry. A similar effect of the atmospheric chemistry has been reported by Dietmüller et al. (2014). With the ECHAM/MESSy Atmospheric Chemistry (EMAC) 
Table 4. Forcing, feedbacks and ECS (equilibrium climate sensitivity) estimated from abrupt $4 \times \mathrm{CO}_{2}$ simulations and TCR (transient climate sensitivity) derived from experiments with continuous $1 \% \mathrm{yr}^{-1} \mathrm{CO}_{2}$ increase until doubling. Feedbacks are estimated as described in Andrews et al. (2012). CRE: Cloud radiative effect.

\begin{tabular}{|c|c|c|c|c|c|c|c|c|}
\hline \multirow[b]{2}{*}{ Model } & \multicolumn{2}{|c|}{ Radiative forcing $\left(\mathrm{W} \mathrm{m}^{-2}\right)$} & \multicolumn{4}{|c|}{ Climate feedback parameter $-\alpha\left(\mathrm{W} \mathrm{m}^{-2} / \mathrm{K}^{-1}\right)$} & \multirow[b]{2}{*}{ ECS } & \multirow[b]{2}{*}{ TCR } \\
\hline & Fixed-SST & Regression & Net & LW clear sky & SW clear sky & Net CRE & & \\
\hline SOCOL-MPIOM & 7.23 & 6.70 & -0.89 & -1.68 & 0.52 & 0.27 & 3.76 & 1.84 \\
\hline SOCOL-MPIOM_nochem & - & 6.65 & -0.83 & -1.57 & 0.51 & 0.23 & 4.01 & 1.82 \\
\hline ECHAM5-MPIOM & - & 6.81 & -0.63 & -1.49 & 0.65 & 0.21 & 5.41 & 1.82 \\
\hline
\end{tabular}

model they found a reduction of the climate sensitivity parameter by $8.4 \%$ with interactive chemistry in the case of an instantaneous quadrupled $\mathrm{CO}_{2}$ scenario. The reduction is explained by negative feedbacks introduced by the ozone chemistry with influences on the stratospheric water vapour. In our abrupt $4 \times \mathrm{CO}_{2}$ simulation the pattern of ozone anomalies is very similar to Dietmüller et al. (2014), but the anomalies are overall much weaker and do not exceed $5 \%$. The changes in the stratospheric water vapour mixing ratios due to enhanced transport from the troposphere, however, are larger in our simulations and the differences between the simulation with and without interactive chemistry are more pronounced. Another contribution to the higher ECS without interactive chemistry might come from the prescribed ozone concentrations. With increasing temperatures the altitude of the tropopause rises and ozone is shifted from the lower stratosphere to the uppermost levels in the troposphere, where the radiative effect causes a pronounced warming of the upper troposphere (Heinemann, 2009; Dietmüller et al., 2014).

\section{Transient climate simulations}

In this section we present results from an ensemble of transient climate simulations performed with the AOCCM SOCOL-MPIOM for the period 1600-2000. While the preindustrial period is only briefly described, the focus is on the simulated SAT development in the industrial period (18502000).

In comparison to the probability range of a number of NH temperature proxies (Jansen et al., 2007), the simulations show reasonable agreement during the pre-industrial period (Fig. 8). The imprint of the solar forcing, with the two grand solar minima Maunder Minimum (MM, 1645-1715) and Dalton Minimum (DM, 1800-1820), is clearly visible, but within the proxy-based uncertainty range. The spatial pattern of the temperature reduction for the MM and DM, however, reveals too pronounced temperature reductions for many continental regions in comparison to the multi-proxy reconstruction of Mann et al. (2009), in particular in the tropics (not shown).

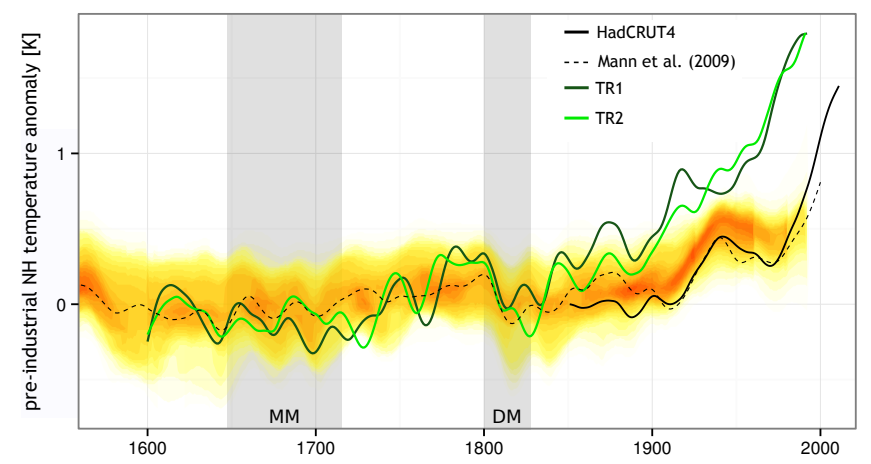

Figure 8. NH mean SAT for the two transient simulations (coloured lines) in comparison to the probability range (yellow/red shading) of different NH temperature reconstructions (Jansen et al., 2007). The NH mean pre-industrial temperature anomaly in the Mann et al. (2009) reconstruction and in HadCRUT4 is also shown. Reconstructions and simulations are given as anomalies to the pre-industrial period 1600-1850. This allows for a direct comparison of the variability in the pre-industrial period despite the strong temperature trend from 1850 on. HadCRUT4 values are displayed relative to the value for the year 1850. All time series are decadally smoothed with a cubic-smoothing spline. Grey bars indicate the Maunder Minimum (MM, 1645-1715) and the Dalton Minimum (DM, 18001820).

\subsection{Temperature trends after 1850}

Since the middle of the 19th century a larger number of instrument-based weather observations are available that allow us to derive global mean SAT (Brohan et al., 2006; Hansen et al., 2010) or to apply them in data assimilation projects (Compo et al., 2011). For a climate model, the ability to reproduce these observed temperature trends is crucial. Therefore, the simulated temperature development since 1850 in the two transient simulations with SOCOL-MPIOM is compared to the observational data sets GISTEMP and HadCRUT4 as well as to the 20th century reanalysis (20CR).

The simulated mean SAT increase since 1850 is much stronger in all transient simulations than in the observations (Fig. 9a). From around 1900 onward temperatures increase more or less linearly with a slight acceleration after 1960. In the observations, the temperature increase is less continuous and divided into an early warming between 1910 and 

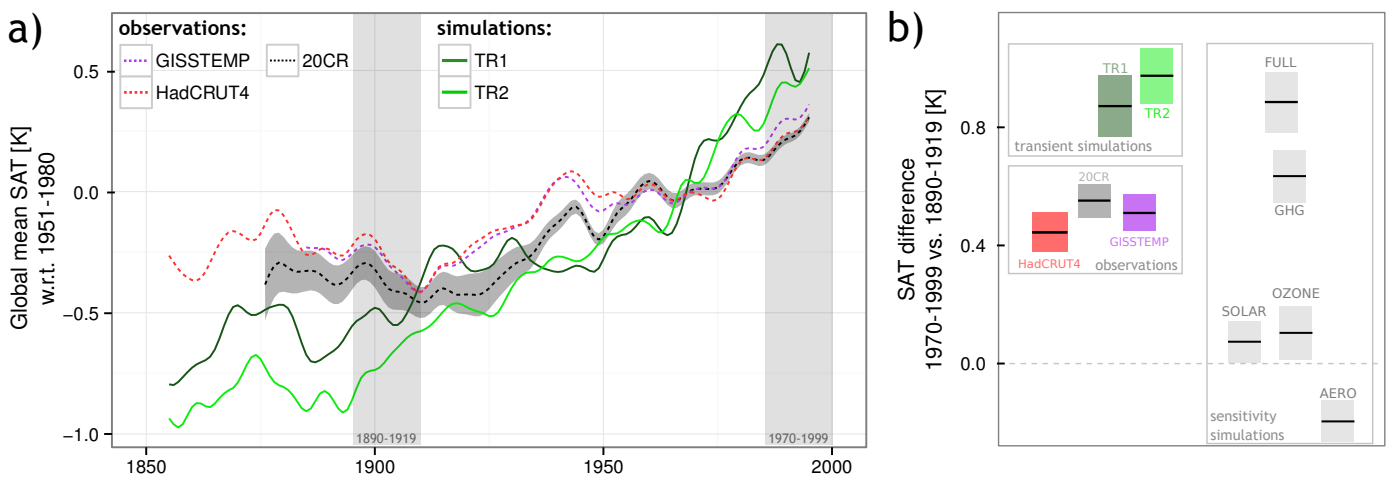

Figure 9. (a) Global mean, annually averaged SAT in the transient simulations and different observation-based data sets. All time series are filtered by an 11-year low-pass filter. For 20CR the ensemble spread (ensemble standard deviation) is indicated by the shaded area. All data sets are given as anomalies w.r.t. the period 1951-1980. (b) Average global mean SAT change from 1890-1919 to 1970-1999 (highlighted by the grey regions in a). TR1 and TR2 refer to the two transient simulations. Bars indicate the average temperature difference between the two periods, grey boxes represent the $95 \%$ confidence intervals.

1940 (Brönnimann, 2009) and a late warming after 1960. This step-wise temperature increase and in particular the suspension of the warming in the middle of the century is not visible in the simulations.

The pattern of the temperature changes might help to identify differences to the observed records. Furthermore, regions with pronounced temperature increase that may be associated with positive feedbacks can be identified. Therefore, we compare the SAT difference between a 30-year period at the beginning (1890-1919) and another at the end of the 20th century (1970-1999). The results are however not sensitive to the exact choice of the periods and a trend pattern analysis also leads to similar results. A comparison of the pattern of the SAT increase in the 20th century is given in Fig. 10. In the observations significant positive temperature changes can be found over the entire globe, interrupted by regions without any changes or significant temperature reductions. Over the oceans a warming is obvious almost everywhere. The largest temperature increases are found in the Southern Ocean at mid-latitudes, reaching around $1 \mathrm{~K}$. In general, differences between the data sets are small over the ocean. This is to some degree expected, since, e.g. 20CR used the same SST data (HadSST) as HadCRUT4 as lower boundary condition. Over the continent, the pattern is spatially more heterogeneous, but regions with significant temperature increases are found on all continents. In 20CR regions with temperature reductions are more pronounced than in the other two data sets - in particular, large differences are found in the $\mathrm{NH}$ and SH polar regions. For 20CR it is known that the Arctic temperature field suffers from a large, time-varying bias (Brönnimann et al., 2012) and an incorrect sea-ice distribution (Compo et al., 2011). However, HadCRUT4 and GISTEMP are also affected by a very low spatial and temporal coverage of instrument-based observations in these regions.
These caveats should be considered when comparing trend estimates for the $\mathrm{NH}$ and $\mathrm{SH}$ polar regions.

In the simulations the strong signal in the global mean SAT is also apparent in the spatial pattern (Fig. 10 shows the average of TR1 and TR2). The warming is too strong in many regions, and spatially very uniform. In the northern polar region, some signals of polar amplification can be found. However, the overestimated increase in the global average SAT is rather related to a strong and uniform warming over the entire globe than to an overestimated polar amplification.

The spatially uniform warming may be related to a specific forcing such as GHG or solar. The TCR of $1.8 \mathrm{~K}$ suggests a moderate temperature increase due to the anthropogenic GHG emissions in the 20th century. Furthermore, results from Anet et al. (2013b) showed that the model response to the future GHG increase (RCP 4.5) is comparable to the CMIP5 ensemble. In their experiments the temperature increase at the end of the 21 th century $(1.96 \pm 0.12 \mathrm{~K})$ is well in the range of the CMIP5 ensemble $(1.8 \pm 0.5 \mathrm{~K}$, e.g. Knutti and Sedláček, 2012). Therefore, other forcings may contribute to the trend in the 20th century and amplify it.

\subsection{Sensitivity to separated external forcings}

The role of different external forcings for the SAT trends since 1850 is investigated using a number of sensitivity simulations where one forcing or a combination of forcings is applied and the remaining forcings are held constant at preindustrial levels (Table 1).

To quantify the contributions of the different forcings to the SAT increase we use again the differences in the global mean SAT between the two 30-year periods defined above (1890-1919 and 1970-1999). In the full forcing experiment the global mean SAT increase agrees well with the increases found in the two transient simulations (Fig. 9b). This gives us confidence that the setup of the sensitivity experiments is 


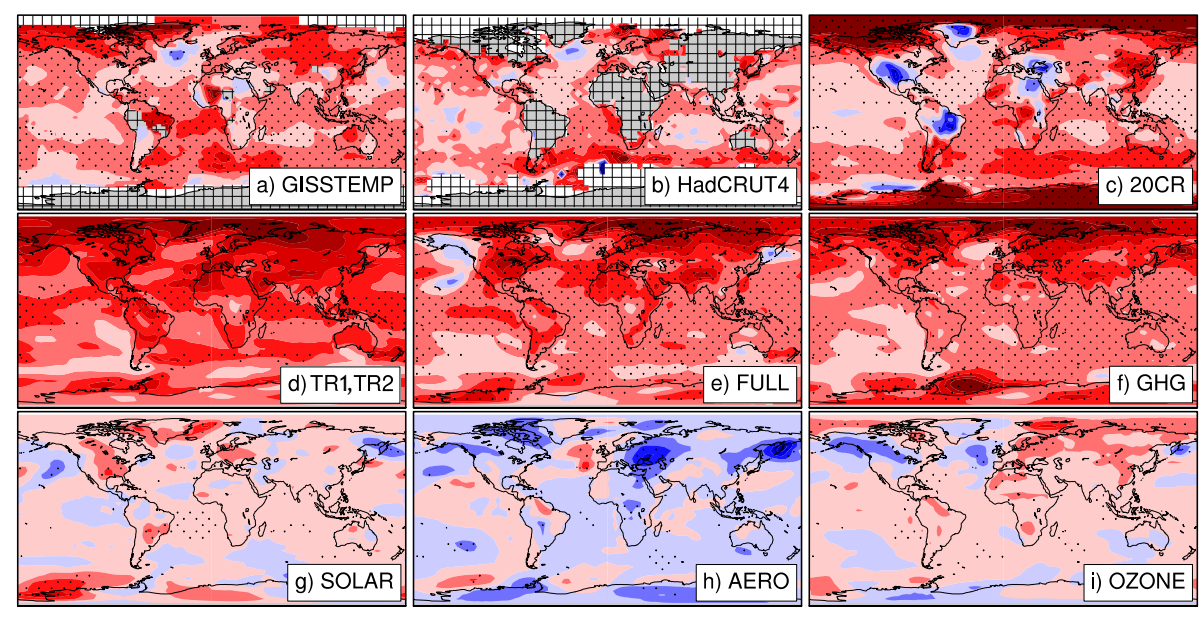

K

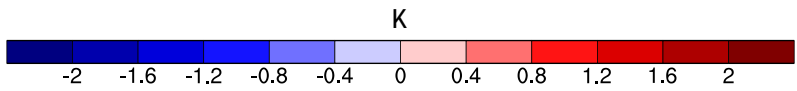

Figure 10. SAT difference [K] between the two 30 yr periods 1890-1919 and 1970-1999 for different data sets and simulations. Top: observational data sets (a) GISSTEMP, (b) HadCRUT4, (c) 20CR. Middle and bottom: model experiments (d) transient simulations TR1 and TR2 - ensemble average (e) full forcing sensitivity run, (f) GHG only, (g) solar only, (h) aerosols only, and (i) ozone only. Stippling: significant differences using a Student's $t$ test $(p \leq 0.05)$ and taking auto-correlation into account following Zwiers and von Storch (1995). For (a) GISSTEMP and (b) HadCRUT4 missing values are indicated by the cross pattern.

able to reproduce the temperature behaviour, when all major forcings are considered. The major part of the temperature increase simulated by all forcings is explained by the GHGs $(72 \%)$. The increasing solar activity $(8 \%)$ and the ozone trends $(12 \%)$ also contribute to the warming. The only negative signal $(-22 \%)$ is related to stratospheric and tropospheric aerosols. All individual forcings (solar, ozone, GHG, aerosols) add up to only $70 \%$ of the full forcing experiment, but given the large uncertainties in the estimates this difference is not significant. Note, however, that the temperature increase due to ozone and solar is only weakly significantly different from zero ( $p=0.09$ and $p=0.07$, respectively).

The spatial structure of the global mean SAT differences for the sensitivity experiments is shown in Fig. 10. The warming in the full forcing experiment is globally very uniform with some hints of polar amplifications in the northern high latitudes. This full forcing pattern is very similar to the changes of the GHG experiment, except for an overall larger trend. As in the global analysis, the temperature change associated with GHGs dominates the full forcing trend almost everywhere. The other three forcings display a much larger spatial heterogeneity and temperature changes are comparably small. The solar experiment, which, on global average, leads to a warming of approximately $0.07 \mathrm{~K}$, has slightly significant contributions, e.g. over northern America, Greenland and Europe. Over Europe and North America the contributions from the solar forcing are clearly visible in the full forcing experiment. Further significant temperature increases are found in the tropical Atlantic and Indian Ocean. The stratospheric and tropospheric aerosol lead to significant negative temperature changes in the tropical continental areas of the
SH and over a large region covering Russia and East Asia. Furthermore, a significant positive influence is found for the North Atlantic. Finally, the simulation forced by transient ozone changes reveals a significant and pronounced positive temperature increase in the $\mathrm{NH}$ high latitudes, which peaks over the Barents Sea. In the SH high latitudes, no comparable signals are found. Overall, several regions of significant positive temperature differences are associated with the ozone changes.

The simulated temperature difference based on the individual forcing is associated with different uncertainties. For the GHG experiment, the forcing during the industrial period is well known. The combined radiative forcing (RF) from $\mathrm{CO}_{2}, \mathrm{CH}_{4}$ and $\mathrm{N}_{2} \mathrm{O}$ (Ramaswamy et al., 2001) is $1.20 \mathrm{~W} \mathrm{~m}^{-2}$ between 1989-1919 and 1970-1999. The simulated response of SOCOL-MPIOM_nochem $(0.63 \mathrm{~K})$ to this RF agrees well with other model estimates (e.g. Meehl et al., 2004). The solar forcing features a clear positive trend in solar activity in the 20th century (mainly in the first half of the century, compare Fig. 1). Between the periods defined above the TOA incoming SW flux increases by $0.28 \mathrm{~W} \mathrm{~m}^{-2}$ (global average assuming a global mean albedo of 0.3 ; stratospheric adjustment was not accounted for). Some uncertainties are associated with this estimate and other reconstructions suggest lower TSI changes. For instance, in the historical CMIP5 simulations the corresponding forcing difference is only $0.09 \mathrm{~W} \mathrm{~m}^{-2}$ (Lean, 2000; Wang et al., 2005). The temperature increase due to the solar forcing can therefore be expected to be larger than in the CMIP5 ensemble. 
Furthermore, ozone is associated with a significant positive temperature change. Observations and model simulations suggest that tropospheric ozone in general increased during the 20th century (Stevenson et al., 2013), whereas reductions of ozone by the emission of ozone depleting halogens occurred in the stratosphere (Staehelin et al., 2001). Both changes have different effects on the radiation balance, with $0.4 \pm 0.2 \mathrm{~W} \mathrm{~m}^{-2}$ for the tropospheric ozone changes and smaller negative contribution of $-0.05 \pm 0.1 \mathrm{~W} \mathrm{~m}^{-2}$ from the stratospheric ozone depletion (Myhre et al., 2013). A direct estimation of the RF associated with the simulated ozone changes is not possible in SOCOL-MPIOM. However, we can compare the simulated ozone changes to estimates from other chemistry-climate models. Global mean tropospheric column ozone (calculated following Shindell et al., 2006) rise by 15 DU between 1989-1919 and 1970-1999. Shindell et al. (2006) estimated an increase of around $10 \mathrm{DU}$ and in the ozone data set used in CMIP5 (Cionni et al., 2011) the tropospheric column ozone change is of the order of $5 \mathrm{DU}$. In a multi-model study with 17 different chemistry-climate models, Stevenson et al. (2013) found an increase of 8.4 DU between 1850 and 2000. Consequently, the effect on the temperature trends is larger, i.e. $0.11 \mathrm{~K}$ in this study and $\sim 0.08 \mathrm{~K}$ in the simulation with the GISS model II (Shindell et al., 2006). However, the chemistry in the GISS model II is limited to levels below $150 \mathrm{hPa}$ and parts of the tropical upper troposphere are not included. This may result in an underestimation of the effect by $20 \%$, as discussed by the authors (Shindell et al., 2006).

The only forcings associated with a negative temperature trend during the 20th century are the stratospheric and tropospheric aerosols $(-0.20 \mathrm{~K})$. Such forcing, however, is associated with larger uncertainties (Boucher et al., 2013). Meehl et al. (2004), who simulated the direct effect of sulfate aerosols only, estimated a similar reduction of the global mean SAT increase of the order of $0.2 \mathrm{~K}$, while Wilcox et al. (2013) find a temperature reduction of about $0.5 \mathrm{~K}$ using a subset of CMIP5 models.

\section{Discussion and conclusions}

This paper presents the coupled atmosphere-chemistryocean model SOCOL-MPIOM. The model is described using results from a number of simulations without changes in the external forcings (control simulations) and with transient external forcings for the period AD 1600-2000.

Without changing boundary conditions the influence of chemistry-climate interactions on the mean climate state and its variability is small and mainly confined to the stratosphere and mesosphere. The largest differences in the temperatures in the middle atmosphere are associated with several processes. First, the parameterisation of the absorption in the Lyman-alpha, Schumann-Runge, Hartley and Higgins bands is responsible for a warmer mesosphere and upper stratosphere in the simulation with interactive chemistry. This parameterisation is disabled in SOCOLMPIOM_nochem, but will be implemented in the next version. Second, interactions between the diurnal variation in the mesospheric ozone concentrations and the radiation scheme lead to a cooling, partly compensating the aforementioned warming. Furthermore, stratospheric water vapour concentrations are higher with interactive chemistry due to the additional water vapour produced by the oxidation of methane in the chemistry module. A future version of the model should therefore implement a parameterisation of this process, e.g. similar to the approach in ECHAM 6 (Schmidt et al., 2013).

The differences between a simulation with and without chemistry-climate feedbacks can be reduced when an adjusted ozone climatology is applied to the model without interactive chemistry. When the ozone climatology is averaged only over daytime conditions, the too high ozone mixing ratios in the mesosphere can be avoided. Ozone data sets which are currently used in GCMs (e.g. Fortuin and Kelder, 1998; Cionni et al., 2011), however, represent the monthly mean conditions. Therefore, we argue that the approach used in this study is a fair comparison of simulations with and without chemistry-climate feedbacks.

Another issue concerns the different time steps used. The dynamical equations are solved every $15 \mathrm{~min}$, which includes the transport of chemical species. The radiation schemes and the chemical module, which are computationally expensive, are solved every $2 \mathrm{~h}$. Within a $2 \mathrm{~h}$ interval the (short-wave) radiative fluxes are linearly interpolated taking the zenith angle into account. Clearly, this might lead to some biases, in particular during sunrise and sunset, when large changes in the reaction rates occur with the availability of UV radiation.

With a TCR of $1.8 \mathrm{~K}$ and an ECS of $3.8 \mathrm{~K}$, SOCOLMPIOM is characterised by a moderate climate sensitivity. The equilibrium response to a change in the $\mathrm{CO}_{2}$ concentrations is further affected by a slight negative feedback of the chemistry, which reduces the ECS by approx. $7 \%$. This is in agreement with results from Dietmüller et al. (2014), although the contributions of ozone and stratospheric water vapour changes differs in our study.

In the industrial period, the GHG increase in combination with a number of different natural and anthropogenic forcings results in an overestimation of the temperature trends up to a factor of 2. Positive contributions to this overestimation are associated with the solar forcing, which may be overestimated. In particular, the TSI increase during the first half of the 20th century in the forcing of Shapiro et al. (2011) is not within the confidence interval of the TSI changes presented in the last IPCC report (Myhre et al., 2013). An additional positive signal comes from the simulated increase in the tropospheric ozone concentrations that also contribute to the global mean temperature trend. However, tropospheric ozone changes during the 20th century are also associated 
with large uncertainties and are therefore difficult to evaluate.

Furthermore, two negative contributors to the 20th century warming trend may be too weak in the simulations. The tropospheric aerosol forcing explains a reduction of the temperature increase of about $0.20 \mathrm{~K}$, while other estimates based in CMIP5 indicate a larger temperature reduction (e.g. Wilcox et al., 2013). Another evidence for an underestimation of the aerosol effect is the fact that the aerosol cooling in the 1950s and 1960s is not visible in the global averaged time series, neither in the full forcing simulations nor in the aerosol only experiment. Since the radiative forcing from tropospheric aerosol-radiation interactions $(-0.35[+0.15$, $-0.85 \mathrm{~W} \mathrm{~m}^{-2}$ ) is associated with large confidence intervals (Boucher et al., 2013), we cannot reject the temperature response of SOCOL-MPIOM. Note, however, that SOCOLMPIOM simulates only the direct aerosol effects on the radiation balance. Large uncertainties are furthermore associated with the radiative forcing and the temperature change from land use changes. In the transient simulations, land use changes are not considered. The estimated radiative forcing may be slightly negative $\left(-0.15 \pm 0.10 \mathrm{~W} \mathrm{~m}^{-2}\right)$, the net temperature response, however, is not necessarily negative (Myhre et al., 2013). A general caveat of the sensitivity simulations is the fact that for each forcing only a single experiment has been performed. Multi-member ensemble simulations might increase the reliability of our results.

When only the radiative forcing from GHGs and the negative contributions from the aerosols are considered, the simulated warming would agree reasonably well with the observations. With the strong additional forcings used here, either the climate sensitivity of SOCOL-MPIOM would need to be lower or possible missing negative forcings would need to be included to match the observed temperature trends.

With the coupling of SOCOL-MPIOM a novel atmosphere-chemistry-ocean model has been developed that allows the inclusion of chemistry-climate feedbacks in long-term simulations for the past and the future. The moderate computational demand of the model even offers the possibility to perform simulations with interactive chemistry feedbacks for the last millennium. Furthermore, with a configuration that allows the deactivation of the chemistry scheme, the influence of the chemistry-climate feedbacks on the climate can be assessed. Earlier studies with SOCOL-MPIOM highlighted the relevance of the atmospheric chemistry in climate model simulations (Anet et al., 2013a, b, 2014; Muthers et al., 2014). Under conditions without a change in the external forcings, the influence of the interactive chemistry on the climate state is small. Future work will concentrate on the role of chemistry-climate feedbacks under changing external forcings.
Acknowledgements. The authors thank the Max-Planck Institute for Meteorology in Hamburg, Germany, in particular Johann Jungclaus and Helmuth Haak, for providing the restart files from the Millennium Simulations and the technical support. We appreciate the constructive comments and questions from the two anonymous reviewers. This work has been supported by the Swiss National Science Foundation under grant CRSI122-130642 (FUPSOL), CRSII2-147659 (FUPSOL II) and under grant CRSI22-130642 21 (FuMES), as well as by the CCES project MAIOLICA-2. E. Rozanov and W. Schmutz would like to acknowledge the support of the project by the State Secretariat for Education, Research and Innovation (SERI) of the Swiss Confederation under the grant C11.01124 (project SOVAC). ECMWF ERA-40 data used in this study have been obtained from the ECMWF Data Server. This paper profited from discussions during the PAGES/FUPSOL Workshop in 2012 and 2014.

Edited by: O. Morgenstern

\section{References}

Andrews, T., Gregory, J. M., Webb, M. J., and Taylor, K. E.: Forcing, feedbacks and climate sensitivity in CMIP5 coupled atmosphere-ocean climate models, Geophys. Res. Lett., 39, L09712, doi:10.1029/2012GL051607, 2012.

Anet, J. G., Muthers, S., Rozanov, E., Raible, C. C., Peter, T., Stenke, A., Shapiro, A. I., Beer, J., Steinhilber, F., Brönnimann, S., Arfeuille, F., Brugnara, Y., and Schmutz, W.: Forcing of stratospheric chemistry and dynamics during the Dalton Minimum, Atmos. Chem. Phys., 13, 10951-10967, doi:10.5194/acp13-10951-2013, 2013a.

Anet, J. G., Rozanov, E. V., Muthers, S., Peter, T., Brönnimann, S., Arfeuille, F., Beer, J., Shapiro, A. I., Raible, C. C., Steinhilber, F., and Schmutz, W. K.: Impact of a potential 21 st century "grand solar minimum" on surface temperatures and stratospheric ozone, Geophys. Res. Lett., 40, 4420-4425, doi:10.1002/grl.50806, 2013b.

Anet, J. G., Muthers, S., Rozanov, E. V., Raible, C. C., Stenke, A., Shapiro, A. I., Brönnimann, S., Arfeuille, F., Brugnara, Y., Beer, J., Steinhilber, F., Schmutz, W., and Peter, T.: Impact of solar versus volcanic activity variations on tropospheric temperatures and precipitation during the Dalton Minimum, Clim. Past, 10, 921-938, doi:10.5194/cp-10-921-2014, 2014.

Arfeuille, F., Weisenstein, D., Mack, H., Rozanov, E., Peter, T., and Brönnimann, S.: Volcanic forcing for climate modeling: a new microphysics-based data set covering years 1600-present, Clim. Past, 10, 359-375, doi:10.5194/cp-10-359-2014, 2014.

Baldwin, M. P. and Dunkerton, T. J.: Propagation of the Arctic Oscillation from the stratosphere to the troposphere, J. Geophys. Res., 104, 30937-30946, doi:10.1029/1999JD900445, 1999.

Baldwin, M. P. and Dunkerton, T. J.: Stratospheric harbingers of anomalous weather regimes, Science, 294, 581-584, doi:10.1126/science.1063315, 2001.

Baldwin, M. P., Cheng, X., and Dunkerton, T. J.: Observed correlations between winter-mean tropospheric and stratospheric circulation anomalies, Geophys. Res. Lett., 21, 1141-1144, 1994.

Baldwin, M. P., Dameris, M., and Shepherd, T. G.: How will the stratosphere affect climate change?, Science, 316, 1576-1577, 2007. 
Baumgaertner, A. J. G., Jöckel, P., and Brühl, C.: Energetic particle precipitation in ECHAM5/MESSy1 - Part 1: Downward transport of upper atmospheric $\mathrm{NO}_{\mathrm{x}}$ produced by low energy electrons, Atmos. Chem. Phys., 9, 2729-2740, doi:10.5194/acp-92729-2009, 2009.

Boucher, O., Randall, D., Artaxo, P., Bretherton, C., Feingold, G., Forster, P., Kerminen, V.-M., Kondo, Y., Liao, H., Lohmann, U., Rasch, P., Satheesh, S. K., Sherwood, S., Stevens, B., and Zhang, X. Y.: Clouds and aerosols, in: Climate Change 2013: The Physical Science Basis. Contribution of Working Group I to the Fifth Assessment Report of the Intergovernmental Panel on Climate Change, edited by: Stocker, T., Qin, D., Plattner, G.-K., Tignor, M., Allen, S., Boschung, J., Nauels, A., Xia, Y., Bex, V., and Midgley, P., chap. 7, Cambridge University Press, Cambridge, United Kingdom and New York, NY, USA, 2013.

Brasseur, G. P. and Solomon, S.: Aeronomy of the middle atmosphere, Kluwer Academic Publishers, Dordrecht, Netherlands, 2005.

Brohan, P., Kennedy, J. J., Harris, I., Tett, S. F. B., and Jones, P. D.: Uncertainty estimates in regional and global observed temperature changes: A new data set from 1850, J. Geophys. Res., 111, D12106, doi:10.1029/2005JD006548, 2006.

Brönnimann, S.: Early twentieth-century warming, Nat. Geosci., 2, 735-736, doi:10.1038/ngeo670, 2009.

Brönnimann, S., Annis, J. L., Vogler, C., and Jones, P. D.: Reconstructing the quasi-biennial oscillation back to the early 1900s, Geophys. Res. Lett., 34, L22805, doi:10.1029/2007GL031354, 2007.

Brönnimann, S., Grant, A. N., Compo, G. P., Ewen, T., Griesser, T., Fischer, A. M., Schraner, M., and Stickler, A.: A multi-data set comparison of the vertical structure of temperature variability and change over the Arctic during the past 100 years, Clim. Dynam., 39, 1577-1598, doi:10.1007/s00382-012-1291-6, 2012.

Budich, R., Gioretta, M., Jungclaus, J., Redler, R., and Reick, C.: The MPI-M Millennium Earth System Model: An assembling guide for the COSMOS configuration, Tech. rep., Max-Planck Institute for Meteorology, Hamburg, Germany, 2010.

Cagnazzo, C., Manzini, E., Giorgetta, M. A., Forster, P. M. De F., and Morcrette, J. J.: Impact of an improved shortwave radiation scheme in the MAECHAM5 General Circulation Model, Atmos. Chem. Phys., 7, 2503-2515, doi:10.5194/acp-7-2503-2007, 2007.

Calisto, M., Usoskin, I., Rozanov, E., and Peter, T.: Influence of Galactic Cosmic Rays on atmospheric composition and dynamics, Atmos. Chem. Phys., 11, 4547-4556, doi:10.5194/acp-114547-2011, 2011.

Charlton, A. J. and Polvani, L. M.: A new look at stratospheric sudden warmings. Part I: Climatology and modeling benchmarks, J. Climate, 20, 449-470, 2007.

Charlton, A. J., Polvani, L. M., Perlwitz, J., Sassi, F., Manzini, E., Shibata, K., Pawson, S., Nielsen, J. E., and Rind, D.: A new look at stratospheric sudden warmings. Part II: Evaluation of numerical model simulations, J. Climate, 20, 470-488, 2007.

Cionni, I., Eyring, V., Lamarque, J. F., Randel, W. J., Stevenson, D. S., Wu, F., Bodeker, G. E., Shepherd, T. G., Shindell, D. T., and Waugh, D. W.: Ozone database in support of CMIP5 simulations: results and corresponding radiative forcing, Atmos. Chem. Phys., 11, 11267-11292, doi:10.5194/acp-11-11267-2011, 2011.
Compo, G. P., Whitaker, J. S., Sardeshmukh, P. D., Matsui, N., A1lan, R. J., Yin, X., Gleason, B. E., Vose, R. S., Rutledge, G., Bessemoulin, P., Brönnimann, S., Brunet, M., Crouthamel, R. I., Grant, A. N., Groisman, P. Y., Jones, P. D., Kruk, M. C., Kruger, A. C., Marshall, G. J., Maugeri, M., Mok, H. Y., Nordli, O., Ross, T. F., Trigo, R. M., Wang, X. L., Woodruff, S. D., and Worley, S. J.: The Twentieth Century Reanalysis project, Quart. J. Roy. Meteor. Soc., 137, 1-28, doi:10.1002/qj.776, 2011.

Cordero, E. C. and Forster, P. M. de F.: Stratospheric variability and trends in models used for the IPCC AR4, Atmos. Chem. Phys., 6, 5369-5380, doi:10.5194/acp-6-5369-2006, 2006.

Cubasch, U., Meehl, G., Boer, G., Stouffer, R., Dix, M., Noda, A., Senior, C., Raper, S., Yap, K., Abe-Ouchi, A., Brinkop, S. Claussen, M., Collins, M., Evans, J., Fischer-Bruns, I., Flato, G., Fyfe, J., Ganopolski, A., Gregory, J., Hu, Z.-Z., Joos, F., Knutson, T., Knutti, R., Landsea, C., Mearns, L., Milly, C., Mitchell, J., Nozawa, T., Paeth, H., Räisänen, J., Sausen, R., Smith, S., Stocker, T., Timmermann, A., Ulbrich, U., Weaver, A., Wegner, J., Whetton, P., Wigley, T., Winton, M., and Zwiers, F.: Projections of future climate change, in: Climate Change 2001: The Scientific Basis, 525-582, Cambridge University Press, 2001.

Dee, D. P., Uppala, S. M., Simmons, A. J., Berrisford, P., Poli, P., Kobayashi, S., Andrae, U., Balmaseda, M. A., Balsamo, G., Bauer, P., Bechtold, P., Beljaars, A. C. M., van de Berg, L., Bidlot, J., Bormann, N., Delsol, C., Dragani, R., Fuentes, M., Geer, A. J., Haimberger, L., Healy, S. B., Hersbach, H., Hólm, E. V., Isaksen, L., Kållberg, P., Köhler, M., Matricardi, M., McNally, A. P., Monge-Sanz, B. M., Morcrette, J.-J., Park, B.-K., Peubey, C., de Rosnay, P., Tavolato, C., Thépaut, J.-N., and Vitart, F.: The ERA-Interim reanalysis: configuration and performance of the data assimilation system, Quart. J. Roy. Meteor. Soc., 137, 553-597, doi:10.1002/qj.828, 2011.

Dietmüller, S., Ponater, M., and Sausen, R.: Interactive ozone induces a negative feedback in $\mathrm{CO} 2$ driven climate change simulations, J. Geophys. Res., 119, 1796-1805, doi:10.1002/2013JD020575, 2014.

Driscoll, S., Bozzo, A., Gray, L. J., Robock, A., and Stenchikov, G.: Coupled Model Intercomparison Project 5 (CMIP5) simulations of climate following volcanic eruptions, J. Geophys. Res., 117, D17105, doi:10.1029/2012JD017607, 2012.

Egorova, T., Rozanov, E., Zubov, V., and Karol, I. L.: Model for investigating ozone trends (MEZON), Izv. Atmos. Ocean. Phys., 39, 277-292, 2003.

Egorova, T., Rozanov, E., Manzini, E., Schmutz, W., and Peter, T.: Chemical and dynamical response to the 11year variability of the solar irradiance simulated with a chemistry-climate model, Geophys. Res. Lett., 83, 6225-6230, doi:10.1029/2003GL019294, 2004.

Etheridge, D., Steele, L., Langenfelds, R., Francey, R., Barnola, J., and Morgan, V.: Natural and anthropogenic changes in atmospheric CO2 over the last 1000 years from air in Antarctic ice and firn, J. Geophys. Res., 101, 4115-4128, doi:10.1029/95JD03410, 1996.

Etheridge, D. M., Steele, L. P., Francey, R. J., and Langenfelds, R. L.: Atmospheric methane between 1000 A.D. and present: Evidence of anthropogenic emissions and climatic variability, J. Geophys. Res., 103, 15979-15993, doi:10.1029/98JD00923, 1998. 
Eyring, V., Butchart, N., Waugh, D. W., Akiyoshi, H., Austin, J., Bekki, S., Bodeker, G. E., Boville, B. A., Brühl, C., Chipperfield, M. P., Cordero, E., Dameris, M., Deushi, M., Fioletov, V. E., Frith, S. M., Garcia, R. R., Gettelman, A., Giorgetta, M. A., Grewe, V., Jourdain, L., Kinnison, D. E., Mancini, E., Manzini, E., Marchand, M., Marsh, D. R., Nagashima, T., Newman, P. A., Nielsen, J. E., Pawson, S., Pitari, G., Plummer, D. A., Rozanov, E., Schraner, M., Shepherd, T. G., Shibata, K., Stolarski, R. S., Struthers, H., Tian, W., and Yoshiki, M.: Assessment of temperature, trace species, and ozone in chemistry-climate model simulations of the recent past, J. Geophys. Res., 111, D22308, doi:10.1029/2006JD007327, 2006.

Ferretti, D. F., Miller, J. B., White, J. W. C., Etheridge, D. M., Lassey, K. R., Lowe, D. C., Meure, C. M. M. F., Dreier, M. F., Trudinger, C. M., Van Ommen, T. D., and Langenfelds, R. L.: Unexpected changes to the global methane budget over the past 2000 years, Science, 309, 1714-1717, doi:10.1126/science.1115193, 2005.

Fischer, A. M., Schraner, M., Rozanov, E., Kenzelmann, P., Schnadt Poberaj, C., Brunner, D., Lustenberger, A., Luo, B. P., Bodeker, G. E., Egorova, T., Schmutz, W., Peter, T., and Brönnimann, S.: Interannual-to-decadal variability of the stratosphere during the 20th century: ensemble simulations with a chemistry-climate model, Atmos. Chem. Phys., 8, 7755-7777, doi:10.5194/acp-87755-2008, 2008..

Flato, G., Marotzke, J., Abiodun, B., Braconnot, P., Chou, S., Collins, W., Cox, P., Driouech, F., Emori, S., Eyring, V., Forest, C., Gleckler, P., Guilyardi, E., Jakob, C., Kattsov, V., Reason, C., and Rummukainen, M.: Evaluation of climate models, in: Climate Change 2013: The Physical Science Basis. Contribution of Working Group I to the Fifth Assess- ment Report of the Intergovernmental Panel on Climate Change, edited by Stocker, T., Qin, D., Plattner, G.-K., Tignor, M., Allen, S., Boschung, J., Nauels, A., Xia, Y., Bex, V., and Midgley, P., chap. 6, 741-866, Cambridge University Press, Cambridge, United Kingdom and New York, NY, USA, 2013.

Fortuin, J. P. F. and Kelder, H.: An ozone climatology based on ozonesonde and satellite measurements, J. Geophys. Res., 31, 31709-31734, 1998.

Fouquart, Y. and Bonnel, B.: Computations of solar heating of the Earth's atmosphere: A new parameterization, Beitr. Phys. Atmos., 53, 35-62, 1980.

Gabriel, A., Peters, D., Kirchner, I., and Graf, H.-F.: Effect of zonally asymmetric ozone on stratospheric temperature and planetary wave propagation, Geophys. Res. Lett., 34, L06807, doi:10.1029/2006GL028998, 2007.

Gerber, E. P., Butler, A., Calvo, N., Charlton-Perez, A., Giorgetta, M., Manzini, E., Perlwitz, J., Polvani, L. M., Sassi, F., Scaife, A. A., Shaw, T. A., Son, S.-W., and Watanabe, S.: Assessing and understanding the impact of stratospheric dynamics and variability on the earth system, B. Am. Meteorol. Soc., 93, 845-859, doi:10.1175/bAms-d-11-00145.1, 2012.

Gillett, N. P. and Thompson, D. W. J.: Simulation of recent southern hemisphere climate change, Science, 302, 273-275, doi:10.1126/science.1087440, 2003.

Gillett, N. P., Allen, M. R., McDonald, R. E., Senior, C. A., Shindell, D. T., and Schmidt, G. A.: How linear is the Arctic Oscillation response to greenhouse gases?, J. Geophys. Res., 107, 1-7, doi:10.1029/2001JD000589, 2002.
Giorgetta, M. A., Bengtsson, L., and Arpe, K.: An investigation of QBO signals in the east Asian and Indian monsoon in GCM experiments, Clim. Dynam., 15, 435-450, doi:10.1007/s003820050292, 1999.

Graversen, R. G. and Christiansen, B.: Downward propagation from the stratosphere to the troposphere: A comparison of the two hemispheres, J. Geophys. Res., 108, 1-10, doi:10.1029/2003JD004077, 2003.

Gregory, J. M., Ingram, W. J., Palmer, M. A., Jones, G. S., Stott, P. A., Thorbe, R. B., Lowe, J. A., Johns, T. C., and Williams, K. D.: A new method for diagnosing radiative forcing and climate sensitivity, Geophys. Res. Lett., 31, L03205, doi:10.1029/2003GL018747, 2004.

Hagemann, S.: An improved land surface parameter dataset for global and regional climate models, Tech. Rep. 336, Max-Planck Institut fuer Meteorologie, Hamburg, Germany, 2002.

Hagemann, S. and Duemenil, L.: A parameterisation of the lateral waterflow for the global scale, Clim. Dynam., 14, 17-31, 1998.

Hagemann, S. and Duemenil-Gates, L.: Improving a subgrid runoff parameterisation scheme for climate models by the use of high resolution data derived from satellite observations, Clim. Dynam., 21, 349-359, 2003.

Haigh, J. D.: The role of stratospheric ozone in modulating the solar radiative forcing of climate, Nature, 370, 544-546, doi:10.1038/370544a0, 1994.

Hansen, J., Ruedy, R., Sato, M., Lo, K., Met Office, and Hadley Center: Global surface temperature change, Rev. Geophys., 48, 1-29, doi:10.1029/2010RG000345, 2010.

Hardiman, S. C., Butchart, N., Hinton, T. J., Osprey, S. M., and Gray, L. J.: The effect of a well-resolved stratosphere on surface climate: Differences between CMIP5 simulations with high and low top versions of the Met Office Climate Model, J. Climate, 25, 7083-7099, doi:10.1175/JCLI-D-11-00579.1, 2012.

Heinemann, M.: Warm and sensitive Paleocene-Eocene climate, Ph.D. thesis, Max-Planck-Institut für Meteorologie, Hamburg, 2009.

Hurrell, J. W.: Decadal trends in the North Atlantic Oscillation: Regional temperatures and precipitation, Science, 269, 676-679, 1995.

Jackman, C. H., Marsh, D. R., Vitt, F. M., Garcia, R. R., Randall, C. E., Fleming, E. L., and Frith, S. M.: Long-term middle atmospheric influence of very large solar proton events, J. Geophys. Res., 114, D11304, doi:10.1029/2008JD011415, 2009.

Jansen, E., Overpeck, J., Briffa, K. R., Duplessy, J.-C., Joos, F., Masson-Delmotte, V., Olago, D., Otto-Bliesner, B., Peltier, W., Rahmstorf, S., Ramesh, R., Raynaud, D., Rind, D., Solomina, O., Villalba, R., Zhang, D., Trenberth, K. E., Jones, P. D., Ambenje, P., Bojariu, R., Easterling, D., Tank, A. K., Parker, D., Rahimzadeh, F., Renwick, J. A., Rusticucci, M., Soden, B., and Zhai, P.: Palaeoclimate, in: Climate Change 2007: The Physical Science Basis. Contribution of Working Group I to the Fourth Assessment Report of the Intergovernmental Panel on Climate Change, edited by Solomon, S., Qin, D., Manning, M., Chen, Z., Marquis, M., Averyt, K. B., Tignor, M., and Miller, H. L., Climate Change 2007: The Physical Science Basis. Contribution of Working Group I to the Fourth Assessment Report of the Intergovernmental Panel on Climate Change, chap. 6, 434-497, Cambridge University Press, Cambridge, United Kingdom and New York, NY, USA, 2007. 
Jungclaus, J. H., Keenlyside, N., Botzet, M., Haak, H., Luo, J.-J., Latif, M., Marotzke, J., Mikolajewicz, U., and Roeckner, E.: Ocean circulation and tropical variability in the coupled model ECHAM5/MPI-OM, J. Climate, 19, 3952-3972, doi:10.1175/JCLI3827.1, 2006.

Jungclaus, J. H., Lorenz, S. J., Timmreck, C., Reick, C. H., Brovkin, V., Six, K., Segschneider, J., Giorgetta, M. A., Crowley, T. J., Pongratz, J., Krivova, N. A., Vieira, L. E., Solanki, S. K., Klocke, D., Botzet, M., Esch, M., Gayler, V., Haak, H., Raddatz, T. J., Roeckner, E., Schnur, R., Widmann, H., Claussen, M., Stevens, B., and Marotzke, J.: Climate and carbon-cycle variability over the last millennium, Clim. Past, 6, 723-737, doi:10.5194/cp-6723-2010, 2010.

Kennedy, J. J., Rayner, N. A., Smith, R. O., Parker, D. E., and Saunby, M.: Reassessing biases and other uncertainties in sea surface temperature observations measured in situ since 1850 : 2. Biases and homogenization, J. Geophys. Res., 116, D14104, doi:10.1029/2010JD015220, 2011.

Kirchner, I., Stenchikov, G. L., Graf, H.-F., Robock, A., and Antuña, J. C.: Climate model simulation of winter warming and summer cooling following the 1991 Mount Pinatubo volcanic eruption, J. Geophys. Res., 104, 19039-19055, doi:10.1029/1999JD900213, 1999.

Knutti, R. and Sedláček, J.: Robustness and uncertainties in the new CMIP5 climate model projections, Nat. Clim. Chang., 3, 369373, doi:10.1038/nclimate1716, 2012.

Kodera, K.: Influence of volcanic eruptions on the troposphere through stratospheric dynamical processes in the Northern Hemisphere winter, J. Geophys. Res., 99, 1273-1282, 1994.

Kolstad, E. W., Breiteig, T., and Scaife, A. A.: The association between stratospheric weak polar vortex events and cold air outbreaks in the Northern Hemisphere, Quart. J. Roy. Meteor. Soc., 136, 886-893, doi:10.1002/qj.620, 2010.

Kopp, G. and Lean, J. L.: A new, lower value of total solar irradiance: Evidence and climate significance, Geophys. Res. Lett., 38, L01706, doi:10.1029/2010GL045777, 2011.

Lean, J.: Evolution of the sun's spectral irradiance since the Maunder Minimum, Geophys. Res. Lett., 27, 2425-2428, doi:10.1029/2000GL000043, 2000.

Li, C., Storch, J.-S., and Marotzke, J.: Deep-ocean heat uptake and equilibrium climate response, Clim. Dynam., 40, 1071-1086, doi:10.1007/s00382-012-1350-z, 2012.

MacFarling-Meure, C., Etheridge, D., Trudinger, C., Steele, P., Langenfelds, R., Van Ommen, T., Smith, A., and Elkins, J.: Law Dome CO2, CH4 and $\mathrm{N} 2 \mathrm{O}$ ice core records extended to 2000 years BP, Geophys. Res. Lett., 33, L14810, doi:10.1029/2006GL026152, 2006.

Mann, M. E., Zhang, Z., Rutherford, S., Bradley, R. S., Hughes, M. K., Shindell, D. T., Ammann, C. M., Faluvegi, G., and Ni, F.: Global signatures and dynamical origins of the Little Ice Age and Medieval Climate Anomaly, Science, 326, 1256-1260, doi:10.1126/science.1177303, 2009.

Manzini, E., Giorgetta, M. A., Esch, M., Kornblueh, L., and Roeckner, E.: The influence of sea surface temperatures on the northern winter stratosphere: Ensemble simulations with the MAECHAM5 Model, J. Climate, 19, 3863-3881, doi:10.1175/JCLI3826.1, 2006.
Marsland, S.: The Max-Planck-Institute global ocean/sea ice model with orthogonal curvilinear coordinates, Ocean. Model., 5, 91127, doi:10.1016/S1463-5003(02)00015-X, 2003.

Mauritsen, T., Stevens, B., Roeckner, E., Crueger, T., Esch, M., Giorgetta, M., Haak, H., Jungclaus, J., Klocke, D., Matei, D., Mikolajewicz, U., Notz, D., Pincus, R., Schmidt, H., and Tomassini, L.: Tuning the climate of a global model, J. Adv. Model. Earth Syst., 4, M00A01, doi:10.1029/2012MS000154, 2012.

Maycock, A. C., Shine, K. P., and Joshi, M. M.: The temperature response to stratospheric water vapour changes, Quart. J. Roy. Meteor. Soc., 137, 1070-1082, doi:10.1002/qj.822, 2011.

Meehl, G. A., Washington, W. M., Ammann, C. M., Arblaster, J. M., Wigley, T. M. L., and Tebaldi, C.: Combinations of natural and anthropogenic forcings in twentieth-century climate., J. Climate, 17, 3721-3727, 2004.

Mlawer, E. J., Taubman, S. J., Brown, P. D., Iaocono, M. J., and Clough, S. A.: Radiative transfer for inhomogeneous atmospheres: RRTM, validated correlated-k model for the longwave, J. Geophys. Res., 102, 663-682, 1997.

Muthers, S., Anet, J. G., Raible, C. C., Brönnimann, S., Rozanov, E., Arfeuille, F., Peter, T., Shapiro, A. I., Beer, J., Steinhilber, F., Brugnara, Y., and Schmutz, W.: Northern hemispheric winter warming pattern after tropical volcanic eruptions: Sensitivity to the ozone climatology, J. Geophys. Res., 110, 1340-1355, doi:10.1002/2013JD020138, 2014.

Myhre, G., Shindell, D., Bréon, F.-M., Collins, W., Fuglestvedt, J., Huang, J., Koch, D., Lamarque, J.-F., Lee, D., Mendoza, B., Nakajima, T., Robock, A., Stephens, G., Takemura, T., and Zhang, H.: Anthropogenic and Natural Radiative Forcing, in: Climate change 2013: The physical science basis. Contribution of working group I to the fifth assessment report of the Intergovernmental Panel on Climate Change, edited by Stocker, T. F., Qin, D., Plattner, G.-K., Tignor, M., Allen, S. K., Boschung, J., Nauels, A., Xia, Y., Bex, V., and Midgley, P., chap. 8, 659-740, Cambridge University Press, Cambridge, United Kingdom and New York, NY, USA, 2013.

Pinto, J. G. and Raible, C. C.: Past and recent changes in the North Atlantic oscillation, Wiley Interdiscip, Rev. Clim. Change, 3, 7990, doi:10.1002/wcc.150, 2012.

Polvani, L. M. and Waugh, D. W.: Upward wave activity flux as a precursor to extreme stratospheric events and subsequent anomalous surface weather regimes, J. Climate, 17, 3548-3554, 2004.

Purich, A. and Son, S.-W.: Impact of Antarctic ozone depletion and recovery on southern hemisphere precipitation, evaporation, and extreme changes, J. Climate, 25, 3145-3154, doi:10.1175/JCLID-11-00383.1, 2012.

Ramaswamy, V., Boucher, O., Haigh, J., Hauglustine, D. ., Haywood, J., Myhre, G., Nakajima, T., Shi, G. Y., and Solomon, S.: Radiative forcing of climate change, in: IPCC Third Assessment Report: Climate Change 2001, edited by: Houghton, J., Ding, Y., Griggs, D., Noguer, M., van der Linden, P., Dai, X., Maskell, K., and Johnson, C., chap. 6, 350-416, Cambridge University Press, Cambridge, United Kingdom and New York, NY, USA, 2001.

Rayner, N. A., Parker, D. E., Horton, E. B., Folland, C. K., Alexander, L. V., Rowell, D. P., Kent, E. C., and Kaplan, A.: Global analyses of sea surface temperature, sea ice, and night marine air temperature since the late nineteenth century, J. Geophys. Res., 108, 4407, doi:10.1029/2002JD002670, 2003. 
Reichler, T., Kim, J., Manzini, E., and Krüger, J.: A stratospheric connection to Atlantic climate variability, Nat. Geosci., 5, 1-5, doi:10.1038/ngeo1586, 2012.

Roeckner, E., Bäuml, G., Bonaventura, L., Brokopf, R., Esch, M., Giorgetta, M., Hagemann, S., Kirchner, I., Kornblueh, L., Manzini, E., Rhodin, A., Schlese, U., Schulzweida, U., and Tompkins, A.: Report No. 349 the atmospheric general circulation model ECHAM5 - Model description, Tech. Rep. 349, MaxPlanck Institute for Meteorology, Hamburg, Germany, 2003.

Roeckner, E., Brokopf, R., Esch, M., Giorgetta, M., Hagemann, S., Kornblueh, L., Manzini, E., Schlese, U., and Schulzweida, U.: Sensitivity of simulated climate to horizontal and vertical resolution in the ECHAM5 atmosphere model, J. Climate, 19, 37713791, 2006.

Rozanov, E., Calisto, M., Egorova, T., Peter, T., and Schmutz, W.: Influence of the precipitating energetic particles on atmospheric chemistry and climate, Surv. Geophys., 33, 483-501, doi:10.1007/s10712-012-9192-0, 2012.

Scaife, A. A., Spangehl, T., Fereday, D. R., Cubasch, U., Langematz, U., Akiyoshi, H., Bekki, S., Braesicke, P., Butchart, N., Chipperfield, M. P., Gettelman, A., Hardiman, S. C., Michou, M., Rozanov, E., and Shepherd, T. G.: Climate change projections and stratosphere-troposphere interaction, Clim. Dynam., 38, 2089-2097, doi:10.1007/s00382-011-1080-7, 2011.

Schmidt, G. A., Jungclaus, J. H., Ammann, C. M., Bard, E., Braconnot, P., Crowley, T. J., Delaygue, G., Joos, F., Krivova, N. A., Muscheler, R., Otto-Bliesner, B. L., Pongratz, J., Shindell, D. T., Solanki, S. K., Steinhilber, F., and Vieira, L. E. A.: Climate forcing reconstructions for use in PMIP simulations of the Last Millennium (v1.1), Geosci. Model Dev., 5, 185-191, doi:10.5194/gmd-5-185-2012, 2012.

Schmidt, H., Rast, S., Bunzel, F., Esch, M., Giorgetta, M., Kinne, S., Krismer, T., Stenchikov, G., Timmreck, C., Tomassini, L., and Walz, M.: Response of the middle atmosphere to anthropogenic and natural forcings in the CMIP5 simulations with the Max Planck Institute Earth system model, J. Adv. Model. Earth Syst., 5, 98-116, doi:10.1002/jame.20014, 2013.

Shapiro, A. I., Schmutz, W., Rozanov, E., Schoell, M., Haberreiter, M., Shapiro, A. V., and Nyeki, S.: A new approach to the long-term reconstruction of the solar irradiance leads to large historical solar forcing, Astron. Astrophys., 529, A67, doi:10.1051/0004-6361/201016173, 2011.

Shindell, D., Rind, D., Balachandran, N., Lean, J., and Lonergan, P.: Solar cycle variability, ozone, and climate, Science, 284, 305308, 1999 .

Shindell, D., Faluvegi, G., Lacis, A., Hansen, J., Ruedy, R., and Aguilar, E.: Role of tropospheric ozone increases in 20th-century climate change, J. Geophys. Res., 111, D08302, doi:10.1029/2005JD006348, 2006.

Shindell, D. T., Schmidt, G. A., Mann, M. E., Rind, D., and Waple, A. M.: Solar forcing of regional climate change during the Maunder Minimum, Science, 294, 2149-2152, doi:10.1126/science.1064363, 2001.

Sigmond, M., Siegmund, P. C., Manzini, E., and Kelder, H.: A simulation of the separate climate effects of middle-atmospheric and tropospheric CO2 doubling, J. Climate, 17, 2352-2367, 2004.

Smith, T. M., Reynolds, R. W., Peterson, T. C., and Lawrimore, J.: Improvements to NOAA's historical merged land-ocean surface temperature analysis (1880-2006), J. Climate, 21, 2283-2296, doi:10.1175/2007JCLI2100.1, 2008.

Son, S.-W., Gerber, E. P., Perlwitz, J., Polvani, L. M., Gillett, N. P., Seo, K.-H., Eyring, V., Shepherd, T. G., Waugh, D., Akiyoshi, H., Austin, J., Baumgaertner, A., Bekki, S., Braesicke, P., Brühl, C., Butchart, N., Chipperfield, M. P., Cugnet, D., Dameris, M., Dhomse, S., Frith, S., Garny, H., Garcia, R., Hardiman, S. C., Jöckel, P., Lamarque, J. F., Mancini, E., Marchand, M., Michou, M., Nakamura, T., Morgenstern, O., Pitari, G., Plummer, D. A., Pyle, J., Rozanov, E., Scinocca, J. F., Shibata, K., Smale, D., Teyssèdre, H., Tian, W., and Yamashita, Y.: Impact of stratospheric ozone on southern Hemisphere circulation change: A multimodel assessment, J. Geophys. Res., 115, D00M07, doi:10.1029/2010JD014271, 2010.

Song, Y. and Robinson, W. A.: Dynamical mechanisms for stratospheric influences on the troposphere, J. Atmos. Sci., 61, 1711-1725, doi:10.1175/15200469(2004)061<1711:DMFSIO>2.0.CO;2, 2004.

Staehelin, J., Harris, N. R. P., Appenzeller, C., and Eberhard, J.: Ozone trends: A review, Rev. Geophys., 39, 231-290, doi:10.1029/1999RG000059, 2001.

Steinhilber, F., Abreu, J. A., and Beer, J.: Solar modulation during the Holocene, Astrophys. Space Sci. Transactions, 4, 1-6, doi:10.5194/astra-4-1-2008, 2008.

Steinhilber, F., Beer, J., and Fröhlich, C.: Total solar irradiance during the Holocene, Geophys. Res. Lett., 36, L19704, doi:10.1029/2009GL040142, 2009.

Stenchikov, G., Hamilton, K., Stouffer, R. J., Robock, A., Ramaswamy, V., Santer, B., and Graf, H.-F.: Arctic Oscillation response to volcanic eruptions in the IPCC AR4 climate models, J Geophys. Res., 111, 1-17, doi:10.1029/2005JD006286, 2006.

Stenke, A., Hoyle, C. R., Luo, B., Rozanov, E., Gröbner, J., Maag, L., Brönnimann, S., and Peter, T.: Climate and chemistry effects of a regional scale nuclear conflict, Atmos. Chem. Phys., 13, 9713-9729, doi:10.5194/acp-13-9713-2013, 2013a.

Stenke, A., Schraner, M., Rozanov, E., Egorova, T., Luo, B., and Peter, T.: The SOCOL version 3.0 chemistry-climate model: description, evaluation, and implications from an advanced transport algorithm, Geosci. Model Dev., 6, 1407-1427, doi:10.5194/gmd-6-1407-2013, 2013b.

Stevenson, D. S., Young, P. J., Naik, V., Lamarque, J.-F., Shindell, D. T., Voulgarakis, A., Skeie, R. B., Dalsoren, S. B., Myhre, G., Berntsen, T. K., Folberth, G. A., Rumbold, S. T., Collins, W. J., MacKenzie, I. A., Doherty, R. M., Zeng, G., van Noije, T. P. C., Strunk, A., Bergmann, D., Cameron-Smith, P., Plummer, D. A., Strode, S. A., Horowitz, L., Lee, Y. H., Szopa, S., Sudo, K., Nagashima, T., Josse, B., Cionni, I., Righi, M., Eyring, V., Conley, A., Bowman, K. W., Wild, O., and Archibald, A.: Tropospheric ozone changes, radiative forcing and attribution to emissions in the Atmospheric Chemistry and Climate Model Intercomparison Project (ACCMIP), Atmos. Chem. Phys., 13, 3063-3085, doi:10.5194/acp-13-3063-2013, 2013.

Thompson, D. W. J., Baldwin, M. P., and Solomon, S.: Stratospheretroposphere coupling in the southern Hemisphere, J. Atmos. Sci., 62, 708-715, 2005.

Thompson, D. W. J., Furtado, J. C., and Shepherd, T. G.: On the tropospheric response to anomalous stratospheric wave drag and radiative heating, J. Atmos. Sci., 63, 2616-2629, 2006. 
Thompson, D. W. J., Solomon, S., Kushner, P. J., England, M. H., Grise, K. M., and Karoly, D. J.: Signatures of the Antarctic ozone hole in southern Hemisphere surface climate change, Nat. Geosci., 4, 741-749, doi:10.1038/ngeo1296, 2011.

Uppala, S. M., Kållberg, P. W., Simmons, A. J., Andrae, U., Bechtold, V. D. C., Fiorino, M., Gibson, J. K., Haseler, J., Hernandez, A., Kelly, G. A., Li, X., Onogi, K., Saarinen, S., Sokka, N., Allan, R. P., Andersson, E., Arpe, K., Balmaseda, M. A., Beljaars, A. C. M., Berg, L. V. D., Bidlot, J., Bormann, N., Caires, S., Chevallier, F., Dethof, A., Dragosavac, M., Fisher, M., Fuentes, M., Hagemann, S., Hölm, E., Hoskins, B. J., Isaksen, L., Janssen, P. A. E. M., Jenne, R., Mcnally, A. P., Mahfouf, J.-F., Morcrette, J.-J., Rayner, N. A., Saunders, R. W., Simon, P., Sterl, A., Trenberth, K. E., Untch, A., Vasiljevic, D., Viterbo, P., and Woollen, J.: The ERA-40 re-analysis, Quart. J. Roy. Meteor. Soc., 131, 2961-3012, doi:10.1256/qj.04.176, 2005.

Valcke, S.: The OASIS3 coupler: a European climate modelling community software, Geosci. Model Dev., 6, 373-388, doi:10.5194/gmd-6-373-2013, 2013.

Varma, V., Prange, M., Spangehl, T., Lamy, F., Cubasch, U., and Schulz, M.: Impact of solar-induced stratospheric ozone decline on Southern Hemisphere westerlies during the late Maunder Minimum, Geophys. Res. Lett., 39, L20704, doi:10.1029/2012GL053403, 2012.
Wang, Y., Lean, J. L., and Sheeley Jr., , N. R.: Modeling the sun's magnetic field and irradiance since 1713, Astrophys. J., 625, 522-538, doi:10.1086/429689, 2005.

Wanner, H., Brönnimann, S., Casty, C., Gyalistras, D., Luterbacher, J., Schmutz, C.and Stephenson, D. B., and Xoplaki, E.: North Atlantic Oscillation - concepts and studies, Surv. Geophys., 22, 321-381, doi:10.1023/A:1014217317898, 2001.

Waugh, D. W., Oman, L., Newman, P. A., Stolarski, R. S., Pawson, S., Nielsen, J. E., and Perlwitz, J.: Effect of zonal asymmetries in stratospheric ozone on simulated Southern Hemisphere climate trends, Geophys. Res. Lett., 36, L18701, doi:10.1029/2009GL040419, 2009.

Wilcox, L. J., Highwood, E. J., and Dunstone, N. J.: The influence of anthropogenic aerosol on multi-decadal variations of historical global climate, Environ. Res. Lett., 8, 024033, doi:10.1088/17489326/8/2/024033, 2013.

Zwiers, F. W. and von Storch, H.: Taking serial correlation into account in tests of the mean, J. Climate, 8, 336-351, 1995. 